\title{
ON THE TOPOLOGY OF $D$-METRIC SPACES AND GENERATION OF $D$-METRIC SPACES FROM METRIC SPACES
}

\author{
S. V. R. NAIDU, K. P. R. RAO, and N. SRINIVASA RAO
}

Received 20 November 2003

\begin{abstract}
An example of a $D$-metric space is given, in which $D$-metric convergence does not define a topology and in which a convergent sequence can have infinitely many limits. Certain methods for constructing $D$-metric spaces from a given metric space are developed and are used in constructing (1) an example of a $D$-metric space in which $D$-metric convergence defines a topology which is $T_{1}$ but not Hausdorff, and (2) an example of a $D$-metric space in which $D$ metric convergence defines a metrizable topology but the $D$-metric is not continuous even in a single variable.
\end{abstract}

2000 Mathematics Subject Classification: 54E99.

1. Introduction. Dhage [2] introduced the notion of $D$-metric spaces and claimed that $D$-metric convergence defines a Hausdorff topology and that the $D$-metric is (sequentially) continuous in all the three variables. Many authors (see $[1,2,3,4,5,6,7$, $8,9,10,11,12,13,14])$ have taken these claims for granted and used them in proving fixed point theorems in $D$-metric spaces.

In this paper, we give examples to show that in a $D$-metric space

(1) $D$-metric convergence does not always define a topology,

(2) even when $D$-metric convergence defines a topology, it need not be Hausdorff,

(3) even when $D$-metric convergence defines a metrizable topology, the $D$-metric need not be continuous even in a single variable.

In fact, we develop certain methods for constructing $D$-metric spaces from a given metric space and obtain from them, as by-products, examples illustrating the last two assertions. We also introduce the notions of strong convergence, and very strong convergence in a $D$-metric space and study in a decisive way the mutual implications among the three notions of convergence, strong convergence, and very strong convergence.

Throughout this paper, $\mathbb{R}$ denotes the set of all real numbers, $\mathbb{R}^{+}$the set of all nonnegative real numbers, $\mathbb{N}$ the set of all positive integers, and $\left(\mathbb{R}^{+}\right)^{3^{*}}=\left\{\left(t_{1}, t_{2}, t_{3}\right) \in\right.$ $\left.\left(\mathbb{R}^{+}\right)^{3}: t_{1} \leq t_{2}+t_{3}, t_{2} \leq t_{3}+t_{1}, t_{3} \leq t_{1}+t_{2}\right\}$.

Note 1.1. If $(X, d)$ is a metric space, then $(d(x, y), d(y, z), d(z, x)) \in\left(\mathbb{R}^{+}\right)^{3^{*}}$ for all $x, y, z \in X$.

Definition 1.2 [2]. Let $X$ be a nonempty set. A function $\rho: X \times X \times X \rightarrow[0, \infty)$ is called a $D$-metric on $X$ if

(i) $\rho(x, y, z)=0$ if and only if $x=y=z$ (coincidence), 
(ii) $\rho(x, y, z)=\rho(p(x, y, z))$ for all $x, y, z \in X$ and for any permutation $p(x, y, z)$ of $x, y, z$ (symmetry),

(iii) $\rho(x, y, z) \leq \rho(x, y, a)+\rho(x, a, z)+\rho(a, y, z)$ for all $x, y, z, a \in X$ (tetrahedral inequality).

If $X$ is a nonempty set and $\rho$ is $D$-metric on $X$, then the ordered pair $(X, \rho)$ is called a $D$-metric space. When the $D$-metric $\rho$ is understood, we say that $X$ is a $D$-metric space.

Definition $1.3[2,8]$. A sequence $\left\{x_{n}\right\}$ in a $D$-metric space $(X, \rho)$ is said to be convergent (or $\rho$-convergent) if there exists an element $x$ of $X$ with the following property: given $\varepsilon>0$, there exists an $N \in \mathbb{N}$ such that $\rho\left(x_{m}, x_{n}, x\right)<\varepsilon$ for all $m, n \geq N$. In such a case, $\left\{x_{n}\right\}$ is said to converge to $x$ and $x$ is called a limit of $\left\{x_{n}\right\}$.

Definition $1.4[2,8]$. A sequence $\left\{x_{n}\right\}$ in a $D$-metric space $(X, \rho)$ is said to be Cauchy (or $\rho$-Cauchy) if, given $\varepsilon>0$, there exists an $N \in \mathbb{N}$ such that $\rho\left(x_{m}, x_{n}, x_{p}\right)<\varepsilon$ for all $m, n, p \geq N$.

REMARK 1.5. The definition of $\rho$-Cauchy sequence as given by Dhage [2] appears to be slightly different from Definition 1.4 , but it is actually equivalent to it. It can be shown that in a $D$-metric space every convergent sequence is Cauchy.

DEFINITION 1.6 $[2,8]$. A $D$-metric space $(X, \rho)$ is said to be complete (or $\rho$-complete) if every $\rho$-Cauchy sequence in $X$ is $\rho$-convergent in $X$.

Notation 1.7. For a subset $E$ of a $D$-metric space $(X, \rho), E^{c}$ denotes $\{x \in X$ : there is a sequence in $E$ which converges to $x$ under the $D$-metric $\rho$ \}. For any set $X, P(X)$ denotes the power set of $X$, that is, the collection of all subsets of $X$.

We now give an example of a complete $D$-metric space in which $D$-metric convergence does not define a topology and in which there are convergent sequences with infinitely many limits.

EXAMPLE 1.8. Let $X=A \cup B \cup\{0\}$, where $A=\left\{1 / 2^{n}: n \in \mathbb{N}\right\}$ and $B=\left\{2^{n}: n \in \mathbb{N}\right\}$.

Define $\rho: X \times X \times X \rightarrow \mathbb{R}^{+}$as follows:

(i) $\rho(x, y, z)=0$ if $x=y=z$,

(ii) $\rho(x, y, z)=\min \{\max \{x, y\}, \max \{y, z\}, \max \{z, x\}\}$ if $x, y, z \in A \cup\{0\}, 0$ does not occur more than once among $x, y, z$, and at least two among $x, y, z$ are distinct,

(iii) $\rho(x, y, z)=1$ if 0 and at least one element of $B$ occur among $x, y, z$, or 0 occurs exactly twice among $x, y, z$,

(iv) $\rho(x, y, z)=\min \{x, y, z\}$ if $x, y, z \in A \cup B$ and exactly one element of $B$ occurs exactly once among $x, y, z$,

(v) $\rho(x, y, z)=\min \{\max \{1 / x, 1 / y\}, \max \{1 / y, 1 / z\}, \max \{1 / z, 1 / x\}\}$, if $x, y, z \in A \cup B$ and exactly one element of $A$ occurs exactly once among $x, y, z$,

(vi) $\rho(x, y, z)=|1 / x-1 / y|+|1 / y-1 / z|+|1 / z-1 / x|$ if $x, y, z \in B$.

Then $(X, \rho)$ is a complete $D$-metric space. But $\rho$-convergence does not define a topology on $X$.

Proof. Clearly $\rho$ is symmetric in all the three variables and $\rho(x, y, z)=0$ if and only if $x=y=z$. We note that $\rho(x, y, z) \leq 1$ for all $x, y, z \in X$. Let $x, y, z, u \in X$. 
CASE (i). $x=y=z$.

Then $\rho(x, y, z)=0 \leq \rho(u, y, z)+\rho(x, u, z)+\rho(x, y, u)$.

CASE (ii). $x, y, z \in A \cup\{0\}, 0$ does not occur more than once among $x, y, z$, and at least two among $x, y, z$ are distinct.

We may assume that $x \geq y \geq z$. If $u \in A \cup\{0\}$, then $\rho(x, y, z)=y \leq \rho(u, y, z)+$ $\rho(x, u, z)+\rho(x, y, u)$, since when $u>y, \rho(u, y, z)=y$; when $u=y, \rho(x, y, z)=$ $\rho(x, u, z)$; and when $u<y, \rho(x, y, u)=y$. If $u \in B$, then

$$
\begin{aligned}
\rho(x, y, z) & =y=\min \{x, y, u\}=\rho(x, y, u) \\
& \leq \rho(u, y, z)+\rho(x, u, z)+\rho(x, y, u) .
\end{aligned}
$$

CASE (iii). 0 occurs exactly twice among $x, y, z$.

We may assume that $x=y=0$. Then $z \neq 0$. If $u \in X \backslash\{0\}$, then

$$
\begin{aligned}
\rho(x, y, z) & =\rho(0,0, z)=1=\rho(0,0, u)=\rho(x, y, u) \\
& \leq \rho(u, y, z)+\rho(x, u, z)+\rho(x, y, u) .
\end{aligned}
$$

If $u=0$, then

$$
\begin{aligned}
\rho(x, y, z) & =\rho(0,0, z)=1=\rho(u, y, z) \\
& \leq \rho(u, y, z)+\rho(x, u, z)+\rho(x, y, u) .
\end{aligned}
$$

CASE (iv). 0 and at least one element of $B$ occur among $x, y, z$. We may assume that $x=0$ and $y \in B$. Then

$$
\begin{aligned}
\rho(x, y, z) & =\rho(0, y, z)=1=\rho(0, y, u)=\rho(x, y, u) \\
& \leq \rho(u, y, z)+\rho(x, u, z)+\rho(x, y, u) .
\end{aligned}
$$

CASE (v). $x, y, z \in A \cup B$ and exactly one element of $B$ occurs exactly once among $x$, $y, z$.

We may assume that $x \in B$. Then $y, z \in A$. We may also assume that $y \geq z$. If $u \in B$, then

$$
\begin{aligned}
\rho(x, y, z) & =\min \{x, y, z\}=z=\rho(u, y, z) \\
& \leq \rho(u, y, z)+\rho(x, u, z)+\rho(x, y, u) .
\end{aligned}
$$

If $u \in A \cup\{0\}$, then

$$
\rho(x, y, z)=\min \{x, y, z\}=z \leq \rho(u, y, z)+\rho(x, u, z)+\rho(x, y, u),
$$

since when $u<z, \rho(u, y, z)=z$; when $u=z, \rho(x, y, z)=\rho(x, y, u)$; and when $u>z$, $\rho(u, y, z)=\min \{u, y\} \geq z$.

CASE (vi). $x, y, z \in A \cup B$ and exactly one element of $A$ occurs exactly once among $x$, $y, z$. 
We may assume that $x \in A$. Then $y, z \in B$. We may also assume that $y \geq z$. If $u \in A$, then

$$
\begin{aligned}
\rho(x, y, z) & =\max \left\{\frac{1}{y}, \frac{1}{z}\right\}=\frac{1}{z}=\rho(u, y, z) \\
& \leq \rho(u, y, z)+\rho(x, u, z)+\rho(x, y, u) .
\end{aligned}
$$

If $u=0$, then

$$
\begin{aligned}
\rho(x, y, z) & =\max \left\{\frac{1}{y}, \frac{1}{z}\right\}=\frac{1}{z} \leq \frac{1}{2}<1=\rho(u, y, z) \\
& \leq \rho(u, y, z)+\rho(x, u, z)+\rho(x, y, u) .
\end{aligned}
$$

If $u \in B$, then

$$
\begin{aligned}
\rho(x, y, z) & =\max \left\{\frac{1}{y}, \frac{1}{z}\right\}=\frac{1}{z} \\
& \leq \max \left\{\frac{1}{u}, \frac{1}{z}\right\}=\rho(x, u, z) \\
& \leq \rho(u, y, z)+\rho(x, u, z)+\rho(x, y, u) .
\end{aligned}
$$

CASE (vii). $x, y, z \in B$.

We may assume that $1 / x \geq 1 / y \geq 1 / z$. If $u=0$, then

$$
\begin{aligned}
\rho(x, y, z) & =2\left(\frac{1}{x}-\frac{1}{z}\right)<1=\rho(u, y, z) \\
& \leq \rho(u, y, z)+\rho(x, u, z)+\rho(x, y, u) .
\end{aligned}
$$

If $u \in A$, then

$$
\begin{aligned}
\rho(x, y, z) & =2\left(\frac{1}{x}-\frac{1}{z}\right) \leq \frac{1}{x}+\frac{1}{x} \\
& =\rho(x, u, z)+\rho(x, y, u) \\
& \leq \rho(u, y, z)+\rho(x, u, z)+\rho(x, y, u) .
\end{aligned}
$$

If $u \in B$, then

$$
\begin{aligned}
\rho(x, y, z) & =\left|\frac{1}{x}-\frac{1}{y}\right|+\left|\frac{1}{y}-\frac{1}{z}\right|+\left|\frac{1}{z}-\frac{1}{x}\right| \\
& \leq \rho(u, y, z)+\rho(x, u, z)+\rho(x, y, u)
\end{aligned}
$$

since $|1 / x-1 / y| \leq \rho(x, y, u),|1 / y-1 / z| \leq \rho(u, y, z)$, and $|1 / z-1 / x| \leq \rho(x, u, z)$. Thus, for all $x, y, z, u \in X$, we have $\rho(x, y, z) \leq \rho(u, y, z)+\rho(x, u, z)+\rho(x, y, u)$. Hence $\rho$ is a $D$-metric on $X$.

To show that $(X, \rho)$ is $D$-complete.

Let $\left\{x_{n}\right\}$ be a Cauchy sequence in $X$. 
CASE 1. There exists $N \in \mathbb{N}$ such that $x_{n}=x_{N}$ for all $n \geq N$.

In this case, evidently $\left\{x_{n}\right\}$ converges to $x_{N}$.

CASE 2. Given $N \in \mathbb{N}$, there exist $i, j \in \mathbb{N}$ such that $i>N, j>N$, and $x_{i} \neq x_{j}$.

Then there exists $N_{0} \in \mathbb{N}$ such that $x_{i} \neq 0$ for each $i \geq N_{0}$, since $\rho(0,0, x)=1$, for all $x \in X \backslash\{0\}$, and $\left\{x_{n}\right\}$ is Cauchy.

SubCASE (i). There exists $N_{1} \in \mathbb{N}$ such that $N_{1} \geq N_{0}$ and $x_{i} \in A$ for all $i \geq N_{1}$.

Claim 1.9. $x_{n} \rightarrow 0$ as $n \rightarrow \infty$ in the usual sense.

Suppose the claim does not hold. Then there exists a positive real number $\varepsilon$ such that $x_{n} \geq \varepsilon$ for infinitely many $n \in \mathbb{N}$. Given $N \in \mathbb{N}$, we can choose $i, j, k \in \mathbb{N}$ such that $k>j>i>\max \left\{N, N_{1}\right\}, x_{i} \geq \varepsilon, x_{j} \geq \varepsilon$, and $x_{k} \neq x_{j}$. Then

$$
\rho\left(x_{i}, x_{j}, x_{k}\right)=\min \left\{\max \left\{x_{i}, x_{j}\right\}, \max \left\{x_{j}, x_{k}\right\}, \max \left\{x_{k}, x_{i}\right\}\right\} \geq \varepsilon .
$$

This is a contradiction since $\left\{x_{n}\right\}$ is Cauchy. Hence the claim.

For $m, n \geq N_{1}$ and $a \in A \cup\{0\}$, we have

$$
\begin{aligned}
\rho\left(a, x_{m}, x_{n}\right) & =\min \left\{\max \left\{a, x_{m}\right\}, \max \left\{x_{m}, x_{n}\right\}, \max \left\{x_{n}, a\right\}\right\} \\
& \leq \max \left\{x_{m}, x_{n}\right\} \longrightarrow 0 \text { as } m, n \rightarrow \infty
\end{aligned}
$$

Hence $\left\{x_{n}\right\}$ converges to $a$ for any $a \in A \cup\{0\}$. It can also be shown that $\left\{x_{n}\right\}$ converges to $b$ for any $b \in B$.

SubCASE (ii). There exists $N_{2} \in \mathbb{N}$ such that $N_{2} \geq N_{0}$ and $x_{i} \in B$ for all $i \geq N_{2}$.

Claim 1.10. $x_{n} \rightarrow+\infty$ as $n \rightarrow+\infty$.

Suppose the claim does not hold. Then there exists a positive real number $M$ such that $x_{n} \leq M$ for infinitely many $n \in \mathbb{N}$. Given $N \in \mathbb{N}$, we can find $i, j, k \in \mathbb{N}$ such that $k>j>i>\max \left\{N, N_{2}\right\}, x_{i} \leq M, x_{j} \leq M$, and $x_{j} \neq x_{k}$. Then $\rho\left(x_{i}, x_{j}, x_{k}\right) \geq \mid 1 / x_{j}-$ $1 / x_{k} \mid \geq 1 / 2 x_{j} \geq 1 / 2 M$. This is a contradiction since $\left\{x_{n}\right\}$ is Cauchy. Hence the claim.

For $m, n \geq N_{2}$ and $a \in A$, we have

$$
\rho\left(a, x_{m}, x_{n}\right)=\max \left\{\frac{1}{x_{m}}, \frac{1}{x_{n}}\right\} \rightarrow 0 \text { as } m, n \rightarrow \infty
$$

Hence $\left\{x_{n}\right\}$ converges to $a$ for any $a \in A$.

SubCASE (iii). Given $N \in \mathbb{N}$, there exist $i, j \in \mathbb{N}$ such that $i>N, j>N, x_{i} \in A$, and $x_{j} \in B$.

CLAIM 1.11. Any element of A occurs only finitely many times in the sequence $\left\{x_{n}\right\}$.

Suppose the claim does not hold. Then there exists $a_{0} \in A$ such that $a_{0}=x_{n}$ for infinitely many $n \in \mathbb{N}$. Let $N \in \mathbb{N}$. Then there exist $i, j, k \in \mathbb{N}$ such that $k>j>i>N, x_{i}=$ $x_{j}=a_{0}$, and $x_{k} \in B$. Then $\rho\left(x_{i}, x_{j}, x_{k}\right)=\min \left\{x_{i}, x_{j}, x_{k}\right\}=a_{0}$. This is a contradiction since $\left\{x_{n}\right\}$ is Cauchy. Hence the claim. 
ClaIm 1.12. Any element of B occurs only finitely many times in the sequence $\left\{x_{n}\right\}$.

Suppose the claim does not hold. Then there exists $b \in B$ such that $b=x_{n}$ for infinitely many $n \in \mathbb{N}$. Let $N \in \mathbb{N}$. Then there exist $i, j, k \in \mathbb{N}$ such that $k>j>i>N$, $x_{i}=x_{j}=b$, and $x_{k} \in A$. Then $\rho\left(x_{i}, x_{j}, x_{k}\right)=1 / b$. This is a contradiction since $\left\{x_{n}\right\}$ is Cauchy. Hence the claim.

Let $c \in A$. Let $\varepsilon>0$. From Claim 1.11, it follows that there exists $N_{3} \in \mathbb{N}$ such that $x_{n}<\min \{\varepsilon, c\}$ whenever $n \geq N_{3}$ and $x_{n} \in A$. From Claim 1.12, it follows that there exists $N_{4} \in \mathbb{N}$ such that $x_{n}>1 / \varepsilon$ whenever $n \geq N_{4}$ and $x_{n} \in B$. Let $N_{5}=\max \left\{N_{0}, N_{3}, N_{4}\right\}$. Let $m, n \in \mathbb{N}$ be such that $m \geq N_{5}$ and $n \geq N_{5}$. Then $x_{n}, x_{m} \in A \cup B$. If both $x_{n}, x_{m} \in A$, then $\rho\left(c, x_{n}, x_{m}\right)=\max \left\{x_{n}, x_{m}\right\}<\varepsilon$. If both $x_{n}, x_{m} \in B$, then $\rho\left(c, x_{n}, x_{m}\right)=\max \left\{1 / x_{n}\right.$, $\left.1 / x_{m}\right\}<\varepsilon$. Suppose that one of $x_{n}, x_{m}$ belongs to $A$ and the other belongs to $B$. We may assume that $x_{n} \in A$ and $x_{m} \in B$. Then $\rho\left(c, x_{n}, x_{m}\right)=\min \left\{c, x_{n}, x_{m}\right\}=x_{n}<\varepsilon$. Thus $\rho\left(c, x_{n}, x_{m}\right)<\varepsilon$ for all $n, m \geq N_{5}$. Hence $\left\{x_{n}\right\}$ converges to $c$.

Thus, in any case, $\left\{x_{n}\right\}$ is convergent in $X$ with respect to the $D$-metric $\rho$. Hence $(X, \rho)$ is a complete $D$-metric space.

To show that $\left(B^{c}\right)^{c} \neq B^{c}$.

Let $p \in B^{c}$. Then there exists a sequence $\left\{x_{n}\right\}$ in $B$ such that $\left\{x_{n}\right\}$ converges to $p$. Hence $\left\{x_{n}\right\}$ is Cauchy. If there exists $N \in \mathbb{N}$ such that $x_{k}=x_{N}$ for all $k \geq N$, then $\rho\left(p, x_{N}, x_{N}\right)=0$ and hence $p=x_{N} \in B$.

Suppose that such an $N$ does not exist. Then given $N \in \mathbb{N}$, there exist $i, j \in \mathbb{N}$ such that $i>N, j>N$, and $x_{i} \neq x_{j}$. As in Subcase (ii) of Case 2 in the proof of the completeness of $\rho$, it can be shown that $x_{n} \rightarrow+\infty$ as $n \rightarrow \infty$ and that $\left\{x_{n}\right\}$ converges to $x$ for any $x \in A$.

For any $x \in B$,

$$
\rho\left(x, x_{n}, x_{m}\right)=\left|\frac{1}{x}-\frac{1}{x_{n}}\right|+\left|\frac{1}{x_{n}}-\frac{1}{x_{m}}\right|+\left|\frac{1}{x_{m}}-\frac{1}{x}\right| \rightarrow \frac{2}{x} \quad \text { as } m, n \rightarrow \infty .
$$

Hence $\left\{x_{n}\right\}$ does not converge to $x$ for any $x \in B$. We have $\rho\left(0, x_{n}, x_{m}\right)=1$ for all $m, n \in \mathbb{N}$. Therefore $\left\{x_{n}\right\}$ does not converge to 0 . Hence $p \in A$. Thus $B^{c} \subseteq B \cup A$. Clearly $B \subseteq B^{c} .\left\{2^{n}\right\}$ converges to $x$ for any $x$ in $A$. Hence $A \subseteq B^{c}$. Therefore $A \cup B=B^{c}$. Since $\left\{1 / 2^{n}\right\}$ is a sequence in $A$ and it converges to $x$ for any $x \in X,\left(B^{c}\right)^{c}=X$. Since $0 \notin A \cup B$, $\left(B^{c}\right)^{c} \neq B^{c}$. Therefore the function $f: P(X) \rightarrow P(X)$ defined as $f(E)=E^{c}$ for all $E \in P(X)$ is not a closure operator. Hence $\rho$-convergence does not define a topology on $X$.

Definition 1.13. Let $(X, \rho)$ be a $D$-metric space and $\left\{x_{n}\right\}$ a sequence in $X$. $\left\{x_{n}\right\}$ is said to converge strongly to an element $x$ of $X$ if

(i) $\rho\left(x, x_{m}, x_{n}\right) \rightarrow 0$ as $m, n \rightarrow \infty$,

(ii) $\left\{\rho\left(y, y, x_{n}\right)\right\}$ converges to $\rho(y, y, x)$ for all $y$ in $X$.

In such a case, $x$ is said to be a strong limit of $\left\{x_{n}\right\}$.

Definition 1.14. Let $(X, \rho)$ be a $D$-metric space and $\left\{x_{n}\right\}$ a sequence in $X$. $\left\{x_{n}\right\}$ is said to converge very strongly to an element $x$ of $X$ if

(i) $\rho\left(x, x_{m}, x_{n}\right) \rightarrow 0$ as $m, n \rightarrow \infty$,

(ii) $\left\{\rho\left(y, z, x_{n}\right)\right\}$ converges to $\rho(y, z, x)$ for any elements $y, z$ of $X$.

In such a case, $x$ is said to be a very strong limit of $\left\{x_{n}\right\}$. 
REMARK 1.15. Let $\left\{x_{n}\right\}$ be a sequence in a $D$-metric space $X$ and $x \in X$. If $\left\{x_{n}\right\}$ converges very strongly to $x$, then $\left\{x_{n}\right\}$ converges strongly to $x$. If $\left\{x_{n}\right\}$ converges strongly to $x$, then it converges to $x$ with respect to $\rho$. Examples $1.21,1.39$, and 1.40 show that the converse statements are false.

Proposition 1.16. Let $(X, \rho)$ be a $D$-metric space. Let $\left\{x_{n}\right\}$ be a sequence in $X$ converging to an element $x$ of $X$. Then $\left\{\rho\left(x, x, x_{n}\right)\right\}$ is convergent.

Proof. Since $\left\{x_{n}\right\}$ is convergent, it is $D$-Cauchy. We have $\rho\left(x, x, x_{n}\right) \leq \rho\left(x_{m}, x, x_{n}\right)+$ $\rho\left(x, x_{m}, x_{n}\right)+\rho\left(x, x, x_{m}\right)$. Hence $\rho\left(x, x, x_{n}\right)-\rho\left(x, x, x_{m}\right) \leq 2 \rho\left(x, x_{m}, x_{n}\right)$. Similarly, we have $\rho\left(x, x, x_{m}\right)-\rho\left(x, x, x_{n}\right) \leq 2\left(x, x_{n}, x_{m}\right)$. Hence $\left|\rho\left(x, x, x_{n}\right)-\rho\left(x, x, x_{m}\right)\right| \leq$ $2 \rho\left(x, x_{n}, x_{m}\right)$. Since this inequality is true for all $m, n \in \mathbb{N}$ and $\left\{x_{n}\right\}$ converges to $x$ under the $D$-metric $\rho$, it follows that $\left\{\rho\left(x, x, x_{n}\right)\right\}$ is a Cauchy sequence of real numbers and hence convergent.

REMARK 1.17. Example 1.21 shows that the hypothesis of Proposition 1.16 does not ensure that the limit of $\left\{\rho\left(x, x, x_{n}\right)\right\}$ is $\rho(x, x, x)$.

Proposition 1.18. In a D-metric space, every strongly convergent sequence has a unique strong limit.

Proof. Let $(X, \rho)$ be a $D$-metric space and $\left\{x_{n}\right\}$ a strongly convergent sequence in $X$. Let $y, z$ be strong limits of $\left\{x_{n}\right\}$. Then $\left\{\rho\left(y, y, x_{n}\right)\right\}$ converges to both $\rho(y, y, y)$ and $\rho(y, y, z)$. Hence $\rho(y, y, z)=\rho(y, y, y)=0$. Hence $y=z$.

THEOREM 1.19. Let $(X, d)$ be a metric space, $x_{0} \in X$, and let $A$ be a nonempty subset of $X \backslash\left\{x_{0}\right\}$. Define $\rho: A \times A \times A \rightarrow \mathbb{R}^{+}$as

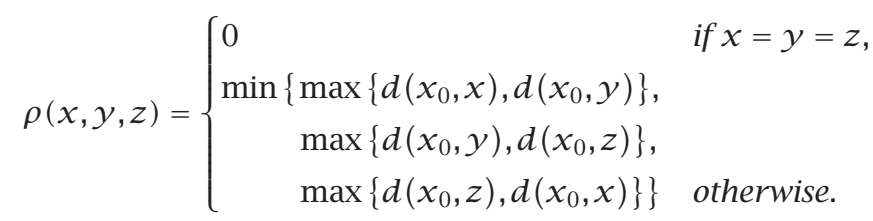

Then $(A, \rho)$ is a complete $D$-metric space and $\rho$-convergence defines a topology $\tau$ on $A$. If $A \cap\left\{x \in X: d\left(x_{0}, x\right)<r_{0}\right\}=\phi$ for some $r_{0} \in(0, \infty)$, then $\tau$ is the discrete topology on $X$; otherwise $\tau=\{\phi\} \cup\left\{E \subseteq A:\left\{x \in A: d\left(x_{0}, x\right)<r\right\} \subseteq E\right.$ for some $\left.r \in(0, \infty)\right\}$ and, in particular, $\tau$ is $T_{1}$ but not Hausdorff.

Let $\left\{x_{n}\right\} \subseteq A$. Then $\left\{x_{n}\right\}$ converges to $x$ with respect to $\rho$ for some $x \in A$ and $x_{n} \neq x$ for all sufficiently large $n \Rightarrow d\left(x_{n}, x_{0}\right) \rightarrow 0$ as $n \rightarrow \infty \Rightarrow\left\{x_{n}\right\}$ converges to $x$ with respect to $\rho$ for each $x$ in A. If $A$ has at least two elements, there does not exist a sequence in $A$ which is strongly convergent with respect to $\rho$.

Proof. Clearly $\rho$ is symmetric in all the three variables and $\rho(x, y, z)=0$ if and only if $x=y=z$. Let $x, y, z, u \in A$. We may assume that $d\left(x_{0}, x\right) \geq d\left(x_{0}, y\right) \geq d\left(x_{0}, z\right)$. Irrespective of whether $d\left(x_{0}, u\right)<d\left(x_{0}, y\right)$ or $d\left(x_{0}, u\right) \geq d\left(x_{0}, y\right)$, we have

$$
\rho(x, y, z)=d\left(x_{0}, y\right) \leq \rho(x, y, u) \text {. }
$$


Hence $\rho(x, y, z) \leq \rho(u, y, z)+\rho(x, u, z)+\rho(x, y, u)$ for all $x, y, z, u \in A$. Hence $\rho$ is a $D$-metric on $A$. Let $\left\{x_{n}\right\}$ be a sequence in $A$ and $x \in A$. If $x_{n} \neq x$, we have

$$
\begin{aligned}
& \rho\left(x, x_{n}, x_{n}\right)=\min \{ \max \left\{d\left(x_{0}, x\right), d\left(x_{0}, x_{n}\right)\right\}, \\
& \max \left\{d\left(x_{0}, x_{n}\right), d\left(x_{0}, x_{n}\right)\right\}, \\
&\left.\max \left\{d\left(x_{0}, x_{n}\right), d\left(x_{0}, x\right)\right\}\right\} \\
& \geq d\left(x_{0}, x_{n}\right) .
\end{aligned}
$$

That is, $\rho\left(x, x_{n}, x_{n}\right) \geq d\left(x_{0}, x_{n}\right)$ if $x_{n} \neq x$. Hence $d\left(x_{0}, x_{n}\right) \rightarrow 0$ as $n \rightarrow \infty$ if $\left\{x_{n}\right\}$ converges to $x$ with respect to $\rho$ for some $x \in A$ and $x_{n} \neq x$ for all sufficiently large $n$. We have

$$
\begin{aligned}
& \rho\left(x_{n}, x_{m}, x\right) \leq \min \{ \max \left\{d\left(x_{0}, x_{n}\right), d\left(x_{0}, x_{m}\right)\right\}, \\
& \max \left\{d\left(x_{0}, x_{m}\right), d\left(x_{0}, x\right)\right\}, \\
&\left.\max \left\{d\left(x_{0}, x\right), d\left(x_{0}, x_{n}\right)\right\}\right\} \\
& \leq \max \left\{d\left(x_{0}, x_{n}\right), d\left(x_{0}, x_{m}\right)\right\} \quad \forall n, m \in \mathbb{N} .
\end{aligned}
$$

Thus $\left\{x_{n}\right\}$ converges to $x$ with respect to $\rho$ for each $x$ in $A$ if $d\left(x_{0}, x_{n}\right) \rightarrow 0$ as $n \rightarrow \infty$.

If $x_{m} \neq x_{n}$, then we have

$$
\begin{aligned}
& \rho\left(x_{n}, x_{m}, x_{n}\right)=\min \{ \max \left\{d\left(x_{0}, x_{n}\right), d\left(x_{0}, x_{m}\right)\right\}, \\
& \max \left\{d\left(x_{0}, x_{m}\right), d\left(x_{0}, x_{n}\right)\right\}, \\
&\left.\max \left\{d\left(x_{0}, x_{n}\right), d\left(x_{0}, x_{n}\right)\right\}\right\} \\
& \geq d\left(x_{0}, x_{n}\right) .
\end{aligned}
$$

Hence $d\left(x_{0}, x_{n}\right) \rightarrow 0$ as $n \rightarrow \infty$ if $\left\{x_{n}\right\}$ is $\rho$-Cauchy and there does not exist an $N \in \mathbb{N}$ such that $x_{n}=x_{N}$ for all $n>N$. If there exists $N \in \mathbb{N}$ such that $x_{n}=x_{N}$ for all $n>N$, then, evidently, $\left\{x_{n}\right\}$ converges to $x_{N}$ with respect to $\rho$.

If such an $N$ does not exist and $\left\{x_{n}\right\}$ is $\rho$-Cauchy, then $d\left(x_{0}, x_{n}\right) \rightarrow 0$ as $n \rightarrow \infty$, and hence $\left\{x_{n}\right\}$ converges to $x$ with respect to $\rho$ for any $x$ in $A$. Hence every $\rho$-Cauchy sequence in $A$ is convergent with respect to $\rho$. Therefore $(A, \rho)$ is $D$-complete. If $x_{n} \neq x$, we have

$$
\begin{aligned}
& \rho\left(x, x, x_{n}\right)=\min \{ \max \left\{d\left(x_{0}, x\right), d\left(x_{0}, x\right)\right\}, \\
& \max \left\{d\left(x_{0}, x\right), d\left(x_{0}, x_{n}\right)\right\}, \\
&\left.\max \left\{d\left(x_{0}, x_{n}\right), d\left(x_{0}, x\right)\right\}\right\} \\
& \geq d\left(x_{0}, x\right) .
\end{aligned}
$$

Since $x \in A \subseteq X \backslash\left\{x_{0}\right\}, d\left(x_{0}, x\right)>0$. Hence $\left\{\rho\left(x, x, x_{n}\right)\right\}$ does not converge to 0 if $x_{n} \neq x$ for infinitely many $n$. Consequently, $\left\{x_{n}\right\}$ is not strongly $\rho$-convergent if $A$ has at least two elements. Let $E$ be a subset of $A$. Clearly, $E \subseteq E^{c}$. 
CASE 1. $E \cap\left\{x \in X: d\left(x, x_{0}\right)<r\right\}=\phi$ for some $r \in(0, \infty)$.

Let $z \in E^{c}$. Then there exists a sequence $\left\{x_{n}\right\}$ in $E$ such that $\left\{x_{n}\right\}$ converges to $z$ with respect to $\rho$. Suppose that $x_{n} \neq z$ for each $n$. Then $d\left(x_{0}, x_{n}\right) \rightarrow 0$ as $n \rightarrow \infty$. Since $\mathrm{E} \cap\left\{x \in X: d\left(x, x_{0}\right)<r\right\}=\phi$, we have $d\left(x, x_{0}\right) \geq r$ for all $x \in E$. Hence $d\left(x_{n}, x_{0}\right) \geq$ $r$ for all $n \in \mathbb{N}$. Therefore $\left\{d\left(x_{n}, x_{0}\right)\right\}$ does not converge to 0 . Thus we arrived at a contradiction. Consequently, $x_{n}=z$ for some $n \in \mathbb{N}$. Hence $z \in E$. Therefore $E^{\mathcal{c}} \subseteq E$. Thus $E=E^{c}$.

CASE 2. Case 1 is false.

Then $E \cap\left\{x \in X: d\left(x, x_{0}\right)<1 / n\right\} \neq \phi$ for each $n \in \mathbb{N}$. Hence there exists a sequence $\left\{u_{n}\right\}$ in $E$ such that $d\left(u_{n}, x_{0}\right)<1 / n$ for all $n \in \mathbb{N}$. Therefore $d\left(u_{n}, x_{0}\right) \rightarrow 0$ as $n \rightarrow \infty$. Hence $\left\{u_{n}\right\}$ converges to $x$ with respect to $\rho$ for each $x$ in $A$. Hence $E^{c}=A$.

CASE (I). $A \cap\left\{x \in X: d\left(x, x_{0}\right)<r_{0}\right\}=\phi$ for some $r_{0} \in(0, \infty)$.

In this case, for any subset $E$ of $A$, we have $E^{c}=E$, and hence $\left(E^{c}\right)^{c}=E^{c}=E$. Thus the function $f$ defined on the power set $P(A)$ of $A$ as $f(E)=E^{c}$ for all $E \in P(A)$ is a closure operator. Therefore $\rho$-convergence defines a topology $\tau$ on $A$ in which every subset of $A$ is closed. Hence $\tau=\{E: E \subseteq A\}$. Consequently, $\tau$ is the discrete topology on $X$.

CASE (II). $A \cap\left\{x \in X: d\left(x, x_{0}\right)<r\right\} \neq \phi$ for any $r \in(0, \infty)$.

In this case, for a subset $E$ of $X$, we have $E^{c}=E$ or $A$ according to whether Case 1 or Case 2 holds. Hence $\left(E^{c}\right)^{c}=E^{c}$ for all $E \in P(A)$. Therefore the function $f$ defined on $P(A)$ as $f(E)=E^{c}$ for all $E \in P(A)$ is a closure operator. Thus $\rho$-convergence defines a topology $\tau$ on $A$ with respect to which a subset $B$ of $A$ is closed if and only if $B=E^{c}$ for some $E \in P(A)$. Hence

$$
\begin{aligned}
T & =\left\{A \backslash E^{c}: E \in P(A)\right\} \\
& =\{\phi\} \cup\left\{E \in P(A):\left\{x \in A: d\left(x_{0}, x\right)<r\right\} \subseteq E \text { for some } r \in(0, \infty)\right\} .
\end{aligned}
$$

If $U_{1}, U_{2}$ are nonempty open sets in $\tau$, then $U_{1} \cap U_{2} \neq \phi$ since there exist $r_{1}, r_{2} \in(0, \infty)$ such that

$$
\left\{x \in A: d\left(x_{0}, x\right)<r_{i}\right\} \subseteq U_{i}, \quad i=1,2 .
$$

Hence $\tau$ is not Hausdorff. Let $p, q$ be distinct elements of $A$. Since $x_{0} \notin A, d\left(p, x_{0}\right)$ and $d\left(q, x_{0}\right)$ are positive real numbers. Let $0<r<\min \left\{d\left(p, x_{0}\right), d\left(q, x_{0}\right)\right\}$. Let $V_{0}=\{x \in$ $\left.A: d\left(x, x_{0}\right)<r\right\}$. Then $V_{0} \cup\{p\}$ is a $\tau$-open subset of $A$ containing $p$ but not $q$, and $V_{0} \cup\{q\}$ is a $\tau$-open subset of $A$ containing $q$ but not $p$. Hence the topology $\tau$ is $T_{1}$.

EXAMPLE 1.20. Let $X=\mathbb{R}$ with the usual metric, $x_{0}=0$, and $A=[1,2]$. Then the function $\rho$ defined in Theorem 1.19 on $A \times A \times A$ reduces to the following:

$$
\rho(x, y, z)= \begin{cases}0 & \text { if } x=y=z, \\ \min \{\max \{x, y\}, \max \{y, z\}, \max \{z, x\}\} & \text { otherwise. }\end{cases}
$$

From Theorem 1.19 it follows that $(A, \rho)$ is a complete $D$-metric space and that $\rho$ convergence defines a topology $\tau$ on $A$, which is the discrete topology on $A$. 
EXAMPLE 1.21. Let $X=\mathbb{R}$ with the usual metric, $x_{0}=0$, and $A=\{1 / n: n \in \mathbb{N}\}$. Then the function $\rho$ defined in Theorem 1.19 on $A \times A \times A$ has the same form as that given in Example 1.20. From Theorem 1.19 it follows that $(A, \rho)$ is a complete $D$-metric space, any sequence in $A$ which converges to zero in the usual sense converges to $x$ with respect to $\rho$ for each $x$ in $A$, and that $\rho$-convergence defines a topology $\tau$ on $A$ with respect to which nonempty subset $E$ of $A$ is open if and only if $E$ contains $\{1 / n: n \in \mathbb{N}$ and $n \geq N\}$ for some $N \in \mathbb{N}$. Further, $\tau$ is $T_{1}$ but not Hausdorff. Let $x_{n}=1 / n$ for all $n \in \mathbb{N}$ and $x_{0}=1 / 2$. Then $\left\{x_{n}\right\}$ converges to $1 / 2$ under the $D$-metric $\rho$. We have $\rho\left(x_{0}, x_{0}, x_{n}\right)=\rho(1 / 2,1 / 2,1 / n)=1 / 2$ for all $n \in \mathbb{N} \backslash\{2\}$. Hence $\left\{\rho\left(x_{0}, x_{0}, x_{n}\right)\right\}$ does not converge to $0=\rho\left(x_{0}, x_{0}, x_{0}\right)$. We note that $\{1 / n\}$ does not converge strongly even though it converges to every element of $X$.

THEOREM 1.22. Let $(X, d)$ be a metric space, $x_{0} \in X$, and let $\left\{x_{n}\right\}$ be a convergent sequence in $X \backslash\left\{x_{0}\right\}$ with limit $x_{0}$, A a proper subset of $X \backslash\left\{x_{0}\right\}$ containing $\left\{x_{n}\right\}$, and $B$ a subset of $X \backslash\left\{x_{0}\right\}$ which contains $A$ properly. Define $\rho: B \times B \times B \rightarrow \mathbb{R}^{+}$as

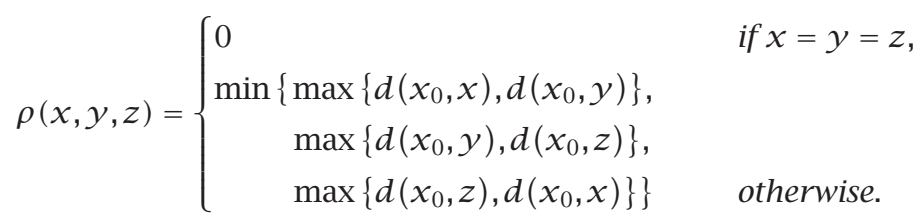

Let $\rho_{0}$ denote the restriction of $\rho$ to $A \times A \times A$. Then $(B, \rho)$ and $\left(A, \rho_{0}\right)$ are complete $D$ metric spaces, $A \subseteq B$, but $\left\{x \in B\right.$ : there is a sequence $\left\{y_{n}\right\}$ in $A$ which converges to $x$ with respect to $\rho\}=B \neq A$.

Proof. The proof follows from Theorem 1.19.

REMARK 1.23. If $(X, d)$ is a metric space, $Y \subseteq X, d_{0}$ is the restriction of $d$ to $Y \times Y$, and $\left(Y, d_{0}\right)$ is complete, then $\left\{x \in X\right.$ : there is a sequence $\left\{y_{n}\right\}$ in $Y$ which converges to $x\}=Y$. Theorem 1.22 shows that an analogous result does not hold in $D$-metric spaces.

THEOREM 1.24. Suppose that $\Phi:\left(\mathbb{R}^{+}\right)^{3^{*}} \rightarrow \mathbb{R}^{+}$is

(i) symmetric in all the three variables,

(ii) $\Phi\left(t_{1}, t_{2}, t_{3}\right)=0$ if and only if $t_{1}=t_{2}=t_{3}=0$,

(iii) $\Phi\left(t_{1}, t_{2}, t_{3}\right) \leq \Phi\left(t_{1}, t_{2}^{\prime}, t_{3}^{\prime}\right)+\Phi\left(t_{1}^{\prime}, t_{2}, t_{3}^{\prime \prime}\right)+\Phi\left(t_{1}^{\prime \prime}, t_{2}^{\prime \prime}, t_{3}\right)$ whenever $\left(t_{1}, t_{2}, t_{3}\right),\left(t_{1}, t_{2}^{\prime}\right.$, $\left.t_{3}^{\prime}\right),\left(t_{1}^{\prime}, t_{2}, t_{3}^{\prime \prime}\right),\left(t_{1}^{\prime \prime}, t_{2}^{\prime \prime}, t_{3}\right) \in\left(\mathbb{R}^{+}\right)^{3^{*}}$ and $t_{i} \leq t_{i}^{\prime}+t_{i}^{\prime \prime}$ for all $i=1,2,3$.

Let $d$ be a metric on $X$ and let $\rho: X \times X \times X \rightarrow \mathbb{R}^{+}$be defined as

$$
\rho(x, y, z)=\Phi(d(x, y), d(y, z), d(z, x)) .
$$

Then $\rho$ is a $D$-metric on $X$. If $\Phi$ is continuous at $(0,0,0)$, then

(1) any $d$-Cauchy sequence in $X$ is $\rho$-Cauchy,

(2) $\left\{x_{n}\right\} \subseteq X, x \in X$, and $d\left(x_{n}, x\right) \rightarrow 0$ as $n \rightarrow \infty \Rightarrow\left\{x_{n}\right\}$ converges to $x$ with respect to the $D$-metric $\rho$.

Suppose that $\Phi$ has the following property:

(iv) given $\varepsilon>0$, there exists $\delta>0$ such that $t<\varepsilon$ whenever $t \in \mathbb{R}^{+}$and $\Phi(0, t, t)<\delta$. 
Then

(1) any $\rho$-Cauchy sequence is $d$-Cauchy,

(2) $\left\{x_{n}\right\}$ ( $\subseteq X$ ) converges to $x \in X$ with respect to $\rho \Rightarrow d\left(x_{n}, x\right) \rightarrow 0$ as $n \rightarrow \infty$.

If $\Phi$ is continuous at $(0,0,0),\left\{\Phi\left(0, t_{n}, t_{n}\right)\right\}$ converges to $\Phi(0, t, t)$ whenever $t \in \mathbb{R}^{+}$, and $\left\{t_{n}\right\}$ is a sequence in $\mathbb{R}^{+}$converging to $t$, then $\left\{x_{n}\right\} \subseteq X, x \in X$, and $d\left(x_{n}, x\right) \rightarrow 0$ as $n \rightarrow \infty \Rightarrow\left\{x_{n}\right\}$ converges strongly to $x$ with respect to the $D$-metric $\rho$.

If $\Phi$ is continuous at $(0,0,0)$ and is continuous in any two variables, then $\left\{x_{n}\right\} \subseteq X$, $x \in X$, and $d\left(x_{n}, x\right) \rightarrow 0$ as $n \rightarrow \infty \Rightarrow\left\{x_{n}\right\}$ converges very strongly to $x$ with respect to the $D$-metric $\rho$.

Proof. We prove that $\rho$ is a $D$-metric on $X$. Since $\Phi$ is symmetric in all the three variables, so is $\rho$. From property (ii) of $\Phi$, it follows that $\rho(x, y, z)=0$ if and only if $x=y=z$.

Let $x, y, z, u \in X$. From property (iii) of $\Phi$, we have

$$
\begin{aligned}
\rho(x, y, z)= & \Phi(d(x, y), d(y, z), d(z, x)) \\
\leq & \Phi(d(x, y), d(y, u), d(u, x)) \\
& +\Phi(d(u, y), d(y, z), d(z, u)) \\
& +\Phi(d(x, u), d(u, z), d(z, x))
\end{aligned}
$$

since $d(x, y) \leq d(u, y)+d(x, u), d(y, z) \leq d(y, u)+d(u, z)$, and $d(z, x) \leq d(u, x)+$ $d(z, u)$. Hence $\rho(x, y, z) \leq \rho(x, y, u)+\rho(u, y, z)+\rho(x, u, z)$ for all $x, y, z, u \in X$. Hence $\rho$ is a $D$-metric on $X$.

Suppose that $\Phi$ is continuous at $(0,0,0)$.

(1) Let $\left\{x_{n}\right\}$ be a $d$-Cauchy sequence in $X$. Then $d\left(x_{n}, x_{m}\right) \rightarrow 0$ as $n, m \rightarrow \infty$. We have

$$
\begin{aligned}
\rho\left(x_{n}, x_{m}, x_{k}\right) & =\Phi\left(d\left(x_{n}, x_{m}\right), d\left(x_{m}, x_{k}\right), d\left(x_{k}, x_{n}\right)\right) \\
& \longrightarrow \Phi(0,0,0)=0 \text { as } n, m, k \longrightarrow \infty \quad(\text { since } \Phi \text { is continuous at }(0,0,0)) .
\end{aligned}
$$

Hence $\left\{x_{n}\right\}$ is $\rho$-Cauchy in $X$.

(2) Let $\left\{x_{n}\right\} \subseteq X$ and let $x \in X$ be such that $d\left(x_{n}, x\right) \rightarrow 0$ as $n \rightarrow \infty$. We have

$$
\begin{aligned}
\rho\left(x, x_{n}, x_{m}\right) & =\Phi\left(d\left(x, x_{n}\right), d\left(x_{n}, x_{m}\right), d\left(x_{m}, x\right)\right) \\
& \longrightarrow \Phi(0,0,0)=0 \quad \text { as } n, m \longrightarrow \infty
\end{aligned}
$$

(since every $d$-convergent sequence is $d$-Cauchy and $\Phi$ is continuous at $(0,0,0)$ ).

Hence $\rho\left(x, x_{n}, x_{m}\right) \rightarrow 0$ as $n, m \rightarrow \infty$. Hence $\left\{x_{n}\right\}$ converges to $x$ with respect to $\rho$. Suppose that $\Phi$ has property (iv).

(1) Let $\left\{x_{n}\right\}$ be a $\rho$-Cauchy sequence in $X$. Let $\varepsilon$ be a positive real number. Then there exists $\delta>0$ such that $t<\varepsilon$ whenever $t \in \mathbb{R}^{+}$and $\Phi(0, t, t)<\delta$. Since $\rho\left(x_{n}, x_{m}\right.$, $\left.x_{n}\right) \rightarrow 0$ as $n, m \rightarrow \infty$, there exists $N \in \mathbb{N}$ such that $\rho\left(x_{n}, x_{m}, x_{n}\right)<\delta$ for all $n, m \geq$ $N$. That is, $\Phi\left(d\left(x_{n}, x_{m}\right), d\left(x_{m}, x_{n}\right), d\left(x_{n}, x_{n}\right)\right)<\delta$ for all $n, m \geq N$. In other words, $\Phi\left(0, d\left(x_{n}, x_{m}\right), d\left(x_{n}, x_{m}\right)\right)<\delta$ for all $n, m \geq N$ (since $\Phi$ is symmetric). Hence $d\left(x_{n}, x_{m}\right)$ $<\varepsilon$ for all $n, m \geq N$. Therefore $\left\{x_{n}\right\}$ is $d$-Cauchy. 
(2) Let $\left\{x_{n}\right\} \subseteq X$ converge to $x \in X$ with respect to the $D$-metric $\rho$. Let $\varepsilon>0$. Then there exists $\delta>0$ such that $t<\varepsilon$ whenever $t \in \mathbb{R}^{+}$and $\Phi(0, t, t)<\delta$. Since $\rho\left(x_{n}, x_{n}, x\right) \rightarrow$ 0 as $n \rightarrow \infty$, there exists $N \in \mathbb{N}$ such that $\rho\left(x_{n}, x_{n}, x\right)<\delta$ for all $n \geq N$. That is, $\Phi\left(d\left(x_{n}, x_{n}\right), d\left(x_{n}, x\right), d\left(x, x_{n}\right)\right)<\delta$ for all $\mathrm{n} \geq N$. That is $\Phi\left(0, d\left(x_{n}, x\right), d\left(x_{n}, x\right)\right)<\delta$ for all $n \geq N$. Hence $d\left(x_{n}, x\right)<\varepsilon$ for all $n \geq N$. Therefore $\left\{x_{n}\right\}$ converges to $x$ with respect to the metric $d$.

Suppose that $\Phi$ is continuous at $(0,0,0)$ and $\left\{\Phi\left(0, t_{n}, t_{n}\right)\right\}$ converges to $\Phi(0, t, t)$ whenever $t \in \mathbb{R}^{+}$and $\left\{t_{n}\right\}$ is a sequence in $\mathbb{R}^{+}$converging to $t$. Let $\left\{x_{n}\right\} \subseteq X$ and let $x \in X$ be such that $d\left(x_{n}, x\right) \rightarrow 0$ as $n \rightarrow \infty$. Let $y \in X$. Then $d\left(x_{n}, y\right) \rightarrow d(x, y)$ as $n \rightarrow \infty$. Hence $\left\{\Phi\left(0, d\left(x_{n}, y\right), d\left(x_{n}, y\right)\right)\right\} \rightarrow \Phi(0, d(x, y), d(x, y))$ as $n \rightarrow \infty$. That is, $\rho\left(y, y, x_{n}\right) \rightarrow \rho(y, y, x)$ as $n \rightarrow \infty$. Since $\Phi$ is continuous at $(0,0,0)$, from what we have already proved, it follows that $\left\{x_{n}\right\}$ converges to $x$ with respect to $\rho$. Hence $\left\{x_{n}\right\}$ converges strongly to $x$ with respect to the $D$-metric $\rho$. Suppose that $\Phi$ is continuous at $(0,0,0)$ and is continuous in any two variables. Let $\left\{x_{n}\right\} \subseteq X$ and let $x \in X$ be such that $d\left(x_{n}, x\right) \rightarrow 0$ as $n \rightarrow \infty$. Let $y, z \in X$. Then $\left\{d\left(z, x_{n}\right)\right\}$ and $\left\{d\left(x_{n}, y\right)\right\}$ converge to $d(z, x)$ and $d(x, y)$, respectively. Since $\Phi$ is continuous in any two variables, it follows that $\left\{\Phi\left(d(y, z), d\left(z, x_{n}\right), d\left(x_{n}, y\right)\right)\right\}$ converges to $\Phi(d(y, z), d(z, x), d(x, y))$, that is, $\left\{\rho\left(y, z, x_{n}\right)\right\}$ converges to $\rho(y, z, x)$. Since $\Phi$ is continuous at $(0,0,0),\left\{x_{n}\right\}$ converges to $x$ with respect to $\rho$. Hence $\left\{x_{n}\right\}$ converges very strongly to $x$ with respect to $\rho$.

CoROLlaRY 1.25. Let $(X, d)$ be a metric space and let $\Phi:\left(\mathbb{R}^{+}\right)^{3^{*}} \rightarrow \mathbb{R}^{+}$be continuous at $(0,0,0)$, and have properties (i), (ii), (iii), and (iv) specified in Theorem 1.24. Let $\rho$ be defined as in Theorem 1.24. Then $\rho$ is a D-metric on $X$, a sequence in $X$ is D-Cauchy if and only if it is $\rho$-Cauchy, and a sequence $\left\{x_{n}\right\}$ in $X$ converges with respect to $d$ to an element $x$ of $X$ if and only if $\left\{x_{n}\right\}$ converges to $x$ with respect to $\rho$. In particular, $\rho$-convergence defines a topology on $X$ which coincides with the metric topology induced by the metric $d$ on $X$, and $X$ is complete with respect to the metric $d$ if and only if it is complete with respect to the D-metric $\rho$. Further, the following statements are true.

(1) If $\left\{\Phi\left(0, t_{n}, t_{n}\right)\right\}$ converges to $\Phi(0, t, t)$ whenever $t \in \mathbb{R}^{+}$and $\left\{t_{n}\right\}$ is a sequence in $\mathbb{R}^{+}$converging to $t,\left\{x_{n}\right\} \subseteq X$, and $x \in X$, then $\left\{x_{n}\right\}$ converges to $x$ with respect to $\rho$ if and only if $\left\{x_{n}\right\}$ converges strongly to $x$ with respect to $\rho$.

(2) If $\Phi$ is continuous in any two variables, $\left\{x_{n}\right\} \subseteq X$, and $x \in X$, then $\left\{x_{n}\right\}$ converges to $x$ with respect to $\rho$ if and only if $\left\{x_{n}\right\}$ converges very strongly to $x$ with respect to $\rho$.

(3) If $\Phi$ is continuous on $\left(\mathbb{R}^{+}\right)^{3^{*}}$, then $\rho$ is sequentially continuous in all the three variables, that is, $\left\{\rho\left(u_{n}, v_{n}, w_{n}\right)\right\}$ converges to $\rho(u, v, w)$ whenever $u, v, w \in X$ and $\left\{u_{n}\right\},\left\{v_{n}\right\}$, and $\left\{w_{n}\right\}$ are sequences in $X$ converging to $u, v$, and $w$, respectively with respect to $\rho$.

NoTE 1.26. Corollary 1.25 is useful in generating a number of $D$-metrics from a given metric on a set.

We now prove a number of propositions which show that the class of functions $\Phi$ : $\left(\mathbb{R}^{+}\right)^{3^{*}} \rightarrow \mathbb{R}^{+}$, which are continuous at $(0, t, t)$ for all $t \in \mathbb{R}^{+}$and which satisfy properties (i), (ii), (iii), and (iv) specified in Theorem 1.24 , is very rich. 
LemmA 1.27. Let $p \in[1, \infty)$. Then $(a+b)^{p} \geq a^{p}+b^{p}$ for all $a, b \in \mathbb{R}^{+}$.

Proof. Define $f: \mathbb{R}^{+} \rightarrow \mathbb{R}$ as $f(t)=(1+t)^{p}-1-t^{p}$ for all $t \in \mathbb{R}^{+}$. Then $f^{\prime}(t)=$ $p(1+t)^{p-1}-p t^{(p-1)}=p\left[(1+t)^{p-1}-t^{(p-1)}\right]$. Since $1+t \geq t$ for all $t \in \mathbb{R}^{+}$and $p-1 \geq 0$, we have $(1+t)^{p-1} \geq t^{(p-1)}$ for all $t \in \mathbb{R}^{+}$.

Hence $f^{\prime}(t) \geq 0$ for all $t \in \mathbb{R}^{+}$. Therefore $f$ is monotonically increasing on $\mathbb{R}^{+}$. We have $f(0)=0$. Hence $f(t) \geq f(0)$ for all $t \in \mathbb{R}^{+}$. Therefore

$$
(1+t)^{p} \geq 1+t^{p} \quad \forall t \in \mathbb{R}^{+}
$$

Let $a, b \in \mathbb{R}^{+}$. We may assume that $a \geq b$. If $a=0$, then $b=0$ and $(a+b)^{p}=0=a^{p}+b^{p}$. Suppose that $a>0$. Then, from what we have already proved above, we have

$$
\left(1+\frac{b}{a}\right)^{p} \geq 1+\left(\frac{b}{a}\right)^{p}
$$

that is,

$$
\left(\frac{a+b}{a}\right)^{p} \geq 1+\frac{b^{p}}{a^{p}}
$$

Hence $(a+b)^{p} \geq a^{p}+b^{p}$.

Corollary 1.28. Let $p \in[1, \infty)$. Then $(a+b+c)^{p} \geq a^{p}+b^{p}+c^{p}$ for all $a, b, c \in \mathbb{R}^{+}$.

Proof. Let $a, b, c \in \mathbb{R}^{+}$. Then, from Lemma 1.27, we have

$$
(a+b+c)^{p}=[(a+b)+c]^{p} \geq(a+b)^{p}+c^{p} \geq a^{p}+b^{p}+c^{p} .
$$

Proposition 1.29. Suppose that $\Psi: \mathbb{R}^{+} \rightarrow \mathbb{R}^{+}$is monotonically increasing and $\Psi(t)=0$ if and only if $t=0$. Let $p \in[1, \infty)$. Define $\Phi:\left(\mathbb{R}^{+}\right)^{3^{*}} \rightarrow \mathbb{R}^{+}$as

$$
\Phi\left(t_{1}, t_{2}, t_{3}\right)=\left[\left[\Psi\left(t_{1}\right)\right]^{p}+\left[\Psi\left(t_{2}\right)\right]^{p}+\left[\Psi\left(t_{3}\right)\right]^{p}\right]^{1 / p} \quad \forall\left(t_{1}, t_{2}, t_{3}\right) \in\left(\mathbb{R}^{+}\right)^{3^{*}}
$$

Then $\Phi$ has properties (i), (ii), (iii), and (iv) specified in Theorem 1.24. If $\Psi$ is continuous at 0 , then $\Phi$ is continuous at $(0,0,0)$, and if $\Psi$ is continuous on $\mathbb{R}^{+}$, then $\Phi$ is continuous on $\left(\mathbb{R}^{+}\right)^{3^{*}}$.

Proof. Clearly $\Phi$ is symmetric in all the three variables:

$$
\begin{aligned}
\Phi\left(t_{1}, t_{2}, t_{3}\right)=0 & \Longleftrightarrow\left[\left[\Psi\left(t_{1}\right)\right]^{p}+\left[\Psi\left(t_{2}\right)\right]^{p}+\left[\Psi\left(t_{3}\right)\right]^{p}\right]^{1 / p}=0 \\
& \Longleftrightarrow\left[\Psi\left(t_{i}\right)\right]^{p}=0 \quad \forall i \\
& \Longleftrightarrow \Psi\left(t_{i}\right)=0 \quad \forall i \\
& \Longleftrightarrow t_{i}=0 \quad \forall i .
\end{aligned}
$$


Let $t_{1}, t_{1}^{\prime}, t_{1}^{\prime \prime}, t_{2}, t_{2}^{\prime}, t_{2}^{\prime \prime}, t_{3}, t_{3}^{\prime}, t_{3}^{\prime \prime} \in \mathbb{R}^{+}$. Let

$$
\begin{aligned}
& a=\left[\left[\Psi\left(t_{1}\right)\right]^{p}+\left[\Psi\left(t_{2}^{\prime}\right)\right]^{p}+\left[\Psi\left(t_{3}^{\prime}\right)\right]^{p}\right]^{1 / p}, \\
& b=\left[\left[\Psi\left(t_{1}^{\prime}\right)\right]^{p}+\left[\Psi\left(t_{2}\right)\right]^{p}+\left[\Psi\left(t_{3}^{\prime \prime}\right)\right]^{p}\right]^{1 / p}, \\
& c=\left[\left[\Psi\left(t_{1}^{\prime \prime}\right)\right]^{p}+\left[\Psi\left(t_{2}^{\prime \prime}\right)\right]^{p}+\left[\Psi\left(t_{3}\right)\right]^{p}\right]^{1 / p} .
\end{aligned}
$$

We have

$$
\begin{aligned}
(a+b+c)^{p} \geq & a^{p}+b^{p}+c^{p} \\
= & {\left[\left[\Psi\left(t_{1}\right)\right]+\left[\Psi\left(t_{2}^{\prime}\right)\right]+\left[\Psi\left(t_{3}^{\prime}\right)\right]\right] } \\
& +\left[\left[\Psi\left(t_{1}^{\prime}\right)\right]^{p}+\left[\Psi\left(t_{2}\right)\right]^{p}+\left[\Psi\left(t_{3}^{\prime \prime}\right)\right]^{p}\right] \\
& +\left[\left[\Psi\left(t_{1}^{\prime \prime}\right)\right]^{p}+\left[\Psi\left(t_{2}^{\prime \prime}\right)\right]^{p}+\left[\Psi\left(t_{3}\right)\right]^{p}\right] \\
\geq & {\left[\Psi\left(t_{1}\right)\right]^{p}+\left[\Psi\left(t_{2}\right)\right]^{p}+\left[\Psi\left(t_{3}\right)\right]^{p} . }
\end{aligned}
$$

Hence $a+b+c \geq\left[\left[\Psi\left(t_{1}\right)\right]^{p}+\left[\Psi\left(t_{2}\right)\right]^{p}+\left[\Psi\left(t_{3}\right)\right]^{p}\right]^{1 / p}$. Therefore $\Phi$ has property (iii). We have

$$
\begin{aligned}
\Phi(0, t, t) & =\left[[\Psi(0)]^{p}+[\Psi(t)]^{p}+[\Psi(t)]^{p}\right]^{1 / p} \\
& =\left[2[\Psi(t)]^{p}\right]^{1 / p} \\
& =2^{1 / p} \Psi(t) .
\end{aligned}
$$

Let $\varepsilon$ be a positive real number. Choose $\delta=2^{1 / p} \Psi(\varepsilon)$. Then $\delta>0$ since $\Psi(t)=0$ implies $t=0$.

$$
\begin{aligned}
\Phi(0, t, t)<\delta & \Longrightarrow 2^{1 / p} \Psi(t)<2^{1 / p} \Psi(\varepsilon) \\
& \Longrightarrow \Psi(t)<\Psi(\varepsilon) \\
& \Longrightarrow t<\varepsilon \quad \text { (since } \Psi \text { is monotonically increasing). }
\end{aligned}
$$

Hence $\Phi$ has property (iv).

Corollary 1.30. Let $p \in[1, \infty)$. Then the function $\Phi:\left(\mathbb{R}^{+}\right)^{3^{*}} \rightarrow \mathbb{R}^{+}$defined as $\Phi\left(t_{1}, t_{2}, t_{3}\right)=\left[t_{1}^{p}+t_{2}^{p}+t_{3}^{p}\right]^{1 / p}$ for all $\left(t_{1}, t_{2}, t_{3}\right) \in\left(\mathbb{R}^{+}\right)^{3^{*}}$ is continuous on $\left(\mathbb{R}^{+}\right)^{3^{*}}$ and has properties (i), (ii), (iii), and (iv) specified in Theorem 1.24.

Proof. The proof follows from Proposition 1.29 by taking $\Psi(t)=t$ for all $t \in \mathbb{R}^{+}$.

Proposition 1.31. Suppose that $\Psi: \mathbb{R}^{+} \rightarrow \mathbb{R}^{+}$is monotonically increasing and $\Psi(t)=0$ if and only if $t=0$. Define $\Phi:\left(\mathbb{R}^{+}\right)^{3^{*}} \rightarrow \mathbb{R}^{+}$as

$$
\Phi\left(t_{1}, t_{2}, t_{3}\right)=\max \left\{\Psi\left(t_{1}\right), \Psi\left(t_{2}\right), \Psi\left(t_{3}\right)\right\} \quad \forall\left(t_{1}, t_{2}, t_{3}\right) \in\left(\mathbb{R}^{+}\right)^{3^{*}}
$$


Then $\Phi$ has properties (i), (ii), (iii), and (iv) specified in Theorem 1.24. If $\Psi$ is continuous at 0 , then $\Phi$ is continuous at $(0,0,0)$, and if $\Psi$ is continuous on $\mathbb{R}^{+}$, then $\Phi$ is continuous on $\left(\mathbb{R}^{+}\right)^{3^{*}}$.

Proof. Clearly $\Phi$ is symmetric in all the three variables.

$$
\begin{aligned}
\Phi\left(t_{1}, t_{2}, t_{3}\right)=0 & \Longleftrightarrow \max \left\{\Psi\left(t_{1}\right), \Psi\left(t_{2}\right), \Psi\left(t_{3}\right)\right\}=0 \\
& \Longleftrightarrow \Psi\left(t_{i}\right)=0 \quad \forall i \\
& \Longleftrightarrow t_{i}=0 \quad \forall i .
\end{aligned}
$$

Hence $\Phi$ has property (ii).

Let $t_{1}, t_{1}^{\prime}, t_{1}^{\prime \prime}, t_{2}, t_{2}^{\prime}, t_{2}^{\prime \prime}, t_{3}, t_{3}^{\prime}, t_{3}^{\prime \prime} \in \mathbb{R}^{+}$. Then

$$
\begin{aligned}
\max \left\{\Psi\left(t_{1}\right), \Psi\left(t_{2}\right), \Psi\left(t_{3}\right)\right\} \leq & \max \left\{\Psi\left(t_{1}\right), \Psi\left(t_{2}^{\prime}\right), \Psi\left(t_{3}^{\prime}\right)\right\} \\
& +\max \left\{\Psi\left(t_{1}^{\prime}\right), \Psi\left(t_{2}\right), \Psi\left(t_{3}^{\prime \prime}\right)\right\} \\
& +\max \left\{\Psi\left(t_{1}^{\prime \prime}\right), \Psi\left(t_{2}^{\prime \prime}\right), \Psi\left(t_{3}\right)\right\}
\end{aligned}
$$

Hence $\Phi$ has property (iii).

Let $\varepsilon$ be a positive real number. Choose $\delta=\Psi(\varepsilon)$. Then $\delta>0$ since $\Psi(t)=0$ implies $t=0$.

$$
\begin{aligned}
\Phi(0, t, t)<\delta & \Longrightarrow \max \{\Psi(0), \Psi(t), \Psi(t)\}<\Psi(\varepsilon) \\
& \Longrightarrow \Psi(t)<\Psi(\varepsilon) \\
& \Longrightarrow t<\varepsilon \quad \text { (since } \Psi \text { is monotonically increasing). }
\end{aligned}
$$

Hence $\Phi$ has property (iv).

Corollary 1.32. The function $\Phi:\left(\mathbb{R}^{+}\right)^{3^{*}} \rightarrow \mathbb{R}^{+}$defined as $\Phi\left(t_{1}, t_{2}, t_{3}\right)=\max \left\{t_{1}, t_{2}\right.$, $\left.t_{3}\right\}$ for all $\left(t_{1}, t_{2}, t_{3}\right) \in\left(\mathbb{R}^{+}\right)^{3^{*}}$ is continuous on $\left(\mathbb{R}^{+}\right)^{3^{*}}$ and has properties (i), (ii), (iii), and (iv) specified in Theorem 1.24.

Proof. The proof follows from Proposition 1.31 by taking $\Psi(t)=t$ for all $t \in \mathbb{R}^{+}$.

Proposition 1.33. Suppose that $\Psi: \mathbb{R}^{+} \rightarrow \mathbb{R}^{+}$is monotonically increasing, $\Psi(s+t) \leq$ $\Psi(s)+\Psi(t)$ for all $s, t \in \mathbb{R}^{+}$, and $\Psi(t)=0$ if and only if $t=0$. Define $\Phi:\left(\mathbb{R}^{+}\right)^{3^{*}} \rightarrow \mathbb{R}^{+}$as

$$
\begin{aligned}
& \Phi\left(t_{1}, t_{2}, t_{3}\right)=\min \{ \max \left\{\Psi\left(t_{1}\right), \Psi\left(t_{2}\right)\right\}, \max \left\{\Psi\left(t_{2}\right), \Psi\left(t_{3}\right)\right\}, \\
&\left.\max \left\{\Psi\left(t_{3}\right), \Psi\left(t_{1}\right)\right\}\right\} \quad \forall\left(t_{1}, t_{2}, t_{3}\right) \in\left(\mathbb{R}^{+}\right)^{3^{*}} .
\end{aligned}
$$


Then $\Phi$ has properties (i), (ii), (iii), and (iv) specified in Theorem 1.24. If $\Psi$ is continuous at 0 , then $\Phi$ is continuous at $(0,0,0)$, and if $\Psi$ is continuous on $\mathbb{R}^{+}$, then $\Phi$ is continuous on $\left(\mathbb{R}^{+}\right)^{3^{*}}$.

Proof. Clearly $\Phi$ is symmetric in all the three variables.

$$
\begin{aligned}
\Phi\left(t_{1}, t_{2}, t_{3}\right)=0 \Longleftrightarrow & \min \left\{\max \left\{\Psi\left(t_{1}\right), \Psi\left(t_{2}\right)\right\}, \max \left\{\Psi\left(t_{2}\right), \Psi\left(t_{3}\right)\right\},\right. \\
& \left.\max \left\{\Psi\left(t_{3}\right), \Psi\left(t_{1}\right)\right\}\right\}=0 \\
\Longleftrightarrow & \max \left\{\Psi\left(t_{1}\right), \Psi\left(t_{2}\right)\right\}=0 \\
& \text { or } \max \left\{\Psi\left(t_{2}\right), \Psi\left(t_{3}\right)\right\}=0 \\
& \text { or } \max \left\{\Psi\left(t_{3}\right), \Psi\left(t_{1}\right)\right\}=0 \\
\Longleftrightarrow & t_{1}=t_{2}=0 \quad \text { or } t_{2}=t_{3}=0 \text { or } t_{3}=t_{1}=0 \\
\Longleftrightarrow & t_{1}=t_{2}=t_{3}=0 \quad\left(\text { since }\left(t_{1}, t_{2}, t_{3}\right) \in\left(\mathbb{R}^{+}\right)^{3^{*}}\right) .
\end{aligned}
$$

Hence $\Phi$ has property (ii).

Let $t_{1}, t_{1}^{\prime}, t_{1}^{\prime \prime}, t_{2}, t_{2}^{\prime}, t_{2}^{\prime \prime}, t_{3}, t_{3}^{\prime}, t_{3}^{\prime \prime} \in \mathbb{R}^{+}$be such that $t_{i} \leq t_{i}^{\prime}+t_{i}^{\prime \prime}$ for all $i=1,2,3$. We have

$$
\begin{aligned}
& \max \left\{\Psi\left(t_{1}\right), \Psi\left(t_{2}^{\prime}\right)\right\}+\max \left\{\Psi\left(t_{1}^{\prime \prime}\right), \Psi\left(t_{2}^{\prime \prime}\right)\right\} \\
& \geq \max \left\{\Psi\left(t_{1}\right), \Psi\left(t_{2}^{\prime}+t_{2}^{\prime \prime}\right)\right\} \quad(\text { since } \Psi(s+t) \leq \Psi(s)+\Psi(t)) \\
& \geq \max \left\{\Psi\left(t_{1}\right), \Psi\left(t_{2}\right)\right\} \quad(\text { since } \Psi \text { is monotonically increasing } \\
&\text { and } \left.t_{2} \leq t_{2}^{\prime}+t_{2}^{\prime \prime}\right) .
\end{aligned}
$$

Clearly, we have

$$
\begin{aligned}
& \max \left\{\Psi\left(t_{1}\right), \Psi\left(t_{2}^{\prime}\right)\right\}+\max \left\{\Psi\left(t_{2}^{\prime \prime}\right), \Psi\left(t_{3}\right)\right\} \geq \max \left\{\Psi\left(t_{1}\right), \Psi\left(t_{3}\right)\right\}, \\
& \max \left\{\Psi\left(t_{1}\right), \Psi\left(t_{2}^{\prime}\right)\right\}+\max \left\{\Psi\left(t_{3}\right), \Psi\left(t_{1}^{\prime \prime}\right)\right\} \geq \max \left\{\Psi\left(t_{1}\right), \Psi\left(t_{3}\right)\right\} .
\end{aligned}
$$

Hence

$$
\begin{gathered}
\max \left\{\Psi\left(t_{1}\right), \Psi\left(t_{2}^{\prime}\right)\right\}+\min \left\{\max \left\{\Psi\left(t_{1}^{\prime \prime}\right), \Psi\left(t_{2}^{\prime \prime}\right)\right\}, \max \left\{\Psi\left(t_{2}^{\prime \prime}\right), \Psi\left(t_{3}\right)\right\},\right. \\
\left.\max \left\{\Psi\left(t_{3}\right), \Psi\left(t_{1}^{\prime \prime}\right)\right\}\right\} \\
\geq \min \left\{\max \left\{\Psi\left(t_{1}\right), \Psi\left(t_{2}\right)\right\}, \max \left\{\Psi\left(t_{1}\right), \Psi\left(t_{3}\right)\right\}\right\} .
\end{gathered}
$$


Similarly,

$\max \left\{\Psi\left(t_{3}^{\prime}\right), \Psi\left(t_{1}\right)\right\}+\min \left\{\max \left\{\Psi\left(t_{1}^{\prime}\right), \Psi\left(t_{2}\right)\right\}, \max \left\{\Psi\left(t_{2}\right), \Psi\left(t_{3}^{\prime \prime}\right)\right\}, \max \left\{\Psi\left(t_{3}^{\prime \prime}\right), \Psi\left(t_{1}^{\prime}\right)\right\}\right\}$

$\geq \min \left\{\max \left\{\Psi\left(t_{1}\right), \Psi\left(t_{2}\right)\right\}, \max \left\{\Psi\left(t_{1}\right), \Psi\left(t_{3}\right)\right\}\right\}$,

$\left.\max \left\{\Psi\left(t_{1}^{\prime}\right), \Psi\left(t_{2}\right)\right\}+\min \left\{\max \left\{\Psi\left(t_{1}^{\prime \prime}\right), \Psi\left(t_{2}^{\prime \prime}\right)\right\}, \max \left\{\Psi\left(t_{2}^{\prime \prime}\right), \Psi\left(t_{3}\right)\right\}, \max \left\{\Psi\left(t_{3}\right)\right\}, \Psi\left(t_{1}^{\prime \prime}\right)\right\}\right\}$

$\geq \min \left\{\max \left\{\Psi\left(t_{1}\right), \Psi\left(t_{2}\right)\right\}, \max \left\{\Psi\left(t_{2}\right), \Psi\left(t_{3}\right)\right\}\right\}$,

$\max \left\{\Psi\left(t_{2}\right), \Psi\left(t_{3}^{\prime \prime}\right)\right\}+\min \left\{\max \left\{\Psi\left(t_{1}\right), \Psi\left(t_{2}^{\prime}\right)\right\}, \max \left\{\Psi\left(t_{2}^{\prime}\right), \Psi\left(t_{3}^{\prime}\right)\right\}, \max \left\{\Psi\left(t_{3}^{\prime}\right), \Psi\left(t_{1}\right)\right\}\right\}$

$\geq \min \left\{\max \left\{\Psi\left(t_{1}\right), \Psi\left(t_{2}\right)\right\}, \max \left\{\Psi\left(t_{2}\right), \Psi\left(t_{3}\right)\right\}\right\}$,

$\max \left\{\Psi\left(t_{2}^{\prime \prime}\right), \Psi\left(t_{3}\right)\right\}+\min \left\{\max \left\{\Psi\left(t_{1}\right), \Psi\left(t_{2}^{\prime}\right)\right\}, \max \left\{\Psi\left(t_{2}^{\prime}\right), \Psi\left(t_{3}^{\prime}\right)\right\}, \max \left\{\Psi\left(t_{3}^{\prime}\right), \Psi\left(t_{1}\right)\right\}\right\}$

$\geq \min \left\{\max \left\{\Psi\left(t_{1}\right), \Psi\left(t_{3}\right)\right\}, \max \left\{\Psi\left(t_{2}\right), \Psi\left(t_{3}\right)\right\}\right\}$,

$\max \left\{\Psi\left(t_{3}\right), \Psi\left(t_{1}^{\prime \prime}\right)\right\}+\min \left\{\max \left\{\Psi\left(t_{1}^{\prime}\right), \Psi\left(t_{2}\right)\right\}, \max \left\{\Psi\left(t_{2}\right), \Psi\left(t_{3}^{\prime \prime}\right)\right\}, \max \left\{\Psi\left(t_{3}^{\prime \prime}\right), \Psi\left(t_{1}^{\prime}\right)\right\}\right\}$

$\geq \min \left\{\max \left\{\Psi\left(t_{1}\right), \Psi\left(t_{3}\right)\right\}, \max \left\{\Psi\left(t_{2}\right), \Psi\left(t_{3}\right)\right\}\right\}$.

We have

$$
\begin{gathered}
\max \left\{\Psi\left(t_{2}^{\prime}\right), \Psi\left(t_{3}^{\prime}\right)\right\}+\max \left\{\Psi\left(t_{3}^{\prime \prime}\right), \Psi\left(t_{1}^{\prime}\right)\right\}+\max \left\{\Psi\left(t_{1}^{\prime \prime}\right), \Psi\left(t_{2}^{\prime \prime}\right)\right\} \\
\geq \max \left\{\max \left\{\Psi\left(t_{3}^{\prime \prime}\right), \Psi\left(t_{1}^{\prime}\right)\right\}+\max \left\{\Psi\left(t_{1}^{\prime \prime}\right), \Psi\left(t_{2}^{\prime \prime}\right)\right\},\right. \\
\quad \max \left\{\Psi\left(t_{2}^{\prime}\right), \Psi\left(t_{3}^{\prime}\right)\right\}+\max \left\{\Psi\left(t_{1}^{\prime \prime}\right), \Psi\left(t_{2}^{\prime \prime}\right)\right\}, \\
\left.\max \left\{\Psi\left(t_{2}^{\prime}\right), \Psi\left(t_{3}^{\prime}\right)\right\}+\max \left\{\Psi\left(t_{3}^{\prime \prime}\right), \Psi\left(t_{1}^{\prime}\right)\right\}\right\} \\
\geq \max \left\{\Psi\left(t_{1}^{\prime}\right)+\Psi\left(t_{1}^{\prime \prime}\right), \Psi\left(t_{2}^{\prime}\right)+\Psi\left(t_{2}^{\prime \prime}\right), \Psi\left(t_{3}^{\prime}\right)+\Psi\left(t_{3}^{\prime \prime}\right)\right\} \\
\geq \max \left\{\Psi\left(t_{1}^{\prime}+t_{1}^{\prime \prime}\right), \Psi\left(t_{2}^{\prime}+t_{2}^{\prime \prime}\right), \Psi\left(t_{3}^{\prime}+t_{3}^{\prime \prime}\right)\right\} \quad\left(\Theta \Psi(s+t) \leq \Psi(s)+\Psi(t) \forall s, t \in \mathbb{R}^{+}\right) \\
\geq \max \left\{\Psi\left(t_{1}\right), \Psi\left(t_{2}\right), \Psi\left(t_{3}\right)\right\} \quad(\text { since } \Psi \text { is monotonically increasing } \\
\text { and } \left.t_{i} \leq t_{i}^{\prime}+t_{i}^{\prime \prime} \forall i=1,2,3\right) .
\end{gathered}
$$

Hence

$$
\begin{aligned}
\min \{ & \left.\max \left\{\Psi\left(t_{1}\right), \Psi\left(t_{2}\right)\right\}, \max \left\{\Psi\left(t_{2}\right), \Psi\left(t_{3}\right)\right\}, \max \left\{\Psi\left(t_{3}\right), \Psi\left(t_{1}\right)\right\}\right\} \\
\leq & \min \left\{\max \left\{\Psi\left(t_{1}\right), \Psi\left(t_{2}^{\prime}\right)\right\}, \max \left\{\Psi\left(t_{2}^{\prime}\right), \Psi\left(t_{3}^{\prime}\right)\right\}, \max \left\{\Psi\left(t_{3}^{\prime}\right), \Psi\left(t_{1}\right)\right\}\right\} \\
& +\min \left\{\max \left\{\Psi\left(t_{1}^{\prime}\right), \Psi\left(t_{2}\right)\right\}, \max \left\{\Psi\left(t_{2}\right), \Psi\left(t_{3}^{\prime \prime}\right)\right\}, \max \left\{\Psi\left(t_{3}^{\prime \prime}\right), \Psi\left(t_{1}^{\prime}\right)\right\}\right\} \\
& +\min \left\{\max \left\{\Psi\left(t_{1}^{\prime \prime}\right), \Psi\left(t_{2}^{\prime \prime}\right)\right\}, \max \left\{\Psi\left(t_{2}^{\prime \prime}\right), \Psi\left(t_{3}\right)\right\}, \max \left\{\Psi\left(t_{3}\right), \Psi\left(t_{1}^{\prime \prime}\right)\right\}\right\} .
\end{aligned}
$$

Therefore $\Phi\left(t_{1}, t_{2}, t_{3}\right) \leq \Phi\left(t_{1}, t_{2}^{\prime}, t_{3}^{\prime}\right)+\Phi\left(t_{1}^{\prime}, t_{2}, t_{3}^{\prime \prime}\right)+\Phi\left(t_{1}^{\prime \prime}, t_{2}^{\prime \prime}, t_{3}\right)$ whenever $\left(t_{1}, t_{2}, t_{3}\right)$, $\left(t_{1}, t_{2}^{\prime}, t_{3}^{\prime}\right),\left(t_{1}^{\prime}, t_{2}, t_{3}^{\prime \prime}\right),\left(t_{1}^{\prime \prime}, t_{2}^{\prime \prime}, t_{3}\right) \in\left(\mathbb{R}^{+}\right)^{3^{*}}$ and $t_{i} \leq t_{i}^{\prime}+t_{i}^{\prime \prime}$ for all $i=1,2,3$. Thus $\Phi$ has property (iii). 
Let $\varepsilon$ be a positive real number. Choose $\delta=\Psi(\varepsilon)$. Then $\delta>0$ since $\Psi(t)=0$ implies $t=0$.

$$
\begin{aligned}
\Phi(0, t, t)<\delta & \Rightarrow \min \{\max \{\Psi(0), \Psi(t)\}, \max \{\Psi(t), \Psi(t)\} \\
& \max \{\Psi(t), \Psi(0)\}\}<\Psi(\varepsilon) \\
\Longrightarrow & \min \{\Psi(t), \Psi(t), \Psi(t)\}<\Psi(\varepsilon) \\
\Longrightarrow & \\
& \Longrightarrow t(t)<\Psi(\varepsilon) \quad \text { (since } \Psi \text { is monotonically increasing). }
\end{aligned}
$$

Hence $\Phi$ has property (iv).

Corollary 1.34. The function $\Phi:\left(\mathbb{R}^{+}\right)^{3^{*}} \rightarrow \mathbb{R}^{+}$defined as $\Phi\left(t_{1}, t_{2}, t_{3}\right)=\min \left\{\max \left\{t_{1}\right.\right.$, $\left.\left.t_{2}\right\}, \max \left\{t_{2}, t_{3}\right\}, \max \left\{t_{3}, t_{1}\right\}\right\}$ for all $\left(t_{1}, t_{2}, t_{3}\right) \in\left(\mathbb{R}^{+}\right)^{3^{*}}$ is continuous on $\left(\mathbb{R}^{+}\right)^{3^{*}}$ and has properties (i), (ii), (iii), and (iv) specified in Theorem 1.24.

Proof. The proof follows from Proposition 1.33 by taking $\Psi(t)=t$ for all $t \in \mathbb{R}^{+}$.

Proposition 1.35. The function $\Phi:\left(\mathbb{R}^{+}\right)^{3^{*}} \rightarrow \mathbb{R}^{+}$defined as

$$
\Phi\left(t_{1}, t_{2}, t_{3}\right)= \begin{cases}t_{1}+t_{2}+t_{3} & \text { if } \min \left\{\left|t_{1}-t_{2}\right|,\left|t_{2}-t_{3}\right|,\left|t_{3}-t_{1}\right|\right\} \leq 1, \\ 1+t_{1}+t_{2}+t_{3} & \text { otherwise, }\end{cases}
$$

has properties (i), (ii), (iii), and (iv) specified in Theorem 1.24 and is continuous at $\left(t_{1}, t_{2}\right.$, $\left.t_{3}\right) \in\left(\mathbb{R}^{+}\right)^{3^{*}}$ if $\min \left\{\left|t_{1}-t_{2}\right|,\left|t_{2}-t_{3}\right|,\left|t_{3}-t_{1}\right|\right\} \neq 1$.

Proof. Clearly $\Phi$ has properties (i) and (ii).

Let $\left(t_{1}, t_{2}, t_{3}\right),\left(t_{1}, t_{2}^{\prime}, t_{3}^{\prime}\right),\left(t_{1}^{\prime}, t_{2}, t_{3}^{\prime \prime}\right),\left(t_{1}^{\prime \prime}, t_{2}^{\prime \prime}, t_{3}\right) \in\left(\mathbb{R}^{+}\right)^{3^{*}}$ be such that $t_{i} \leq t_{i}^{\prime}+t_{i}^{\prime \prime}$ for all $i=1,2,3$.

CASE (i). $\min \left\{\left|t_{1}-t_{2}\right|,\left|t_{2}-t_{3}\right|,\left|t_{3}-t_{1}\right|\right\} \leq 1$.

Then

$$
\begin{aligned}
\Phi\left(t_{1}, t_{2}, t_{3}\right) & =t_{1}+t_{2}+t_{3} \\
& \leq\left(t_{1}+t_{2}^{\prime}+t_{3}^{\prime}\right)+\left(t_{1}^{\prime}+t_{2}+t_{3}^{\prime \prime}\right)+\left(t_{1}^{\prime \prime}+t_{2}^{\prime \prime}+t_{3}\right) \\
& \leq \Phi\left(t_{1}, t_{2}^{\prime}, t_{3}^{\prime}\right)+\Phi\left(t_{1}^{\prime}, t_{2}, t_{3}^{\prime \prime}\right)+\Phi\left(t_{1}^{\prime \prime}, t_{2}^{\prime \prime}, t_{3}\right) .
\end{aligned}
$$

CASE (ii). $\min \left\{\left|t_{1}-t_{2}\right|,\left|t_{2}-t_{3}\right|,\left|t_{3}-t_{1}\right|\right\}>1$.

Then $\max \left\{t_{1}, t_{2}, t_{3}\right\}>1$, hence

$$
\begin{aligned}
\Phi\left(t_{1}, t_{2}, t_{3}\right)= & 1+t_{1}+t_{2}+t_{3} \\
< & 2\left(t_{1}+t_{2}+t_{3}\right) \\
\leq & \left(t_{1}+t_{2}^{\prime}+t_{3}^{\prime}\right)+\left(t_{1}^{\prime}+t_{2}+t_{3}^{\prime \prime}\right)+\left(t_{1}^{\prime \prime}+t_{2}^{\prime \prime}+t_{3}\right) \\
& \left(\text { since } t_{i} \leq t_{i}^{\prime}+t_{i}^{\prime \prime} \forall i=1,2,3\right) . \\
\leq & \Phi\left(t_{1}, t_{2}^{\prime}, t_{3}^{\prime}\right)+\Phi\left(t_{1}^{\prime}, t_{2}, t_{3}^{\prime \prime}\right)+\Phi\left(t_{1}^{\prime \prime}, t_{2}^{\prime \prime}, t_{3}\right) .
\end{aligned}
$$

Thus, in either case, $\Phi\left(t_{1}, t_{2}, t_{3}\right) \leq \Phi\left(t_{1}, t_{2}^{\prime}, t_{3}^{\prime}\right)+\Phi\left(t_{1}^{\prime}, t_{2}, t_{3}^{\prime \prime}\right)+\Phi\left(t_{1}^{\prime \prime}, t_{2}^{\prime \prime}, t_{3}\right)$. Hence $\Phi$ has property (iii). 
Let $\varepsilon$ be a positive real number. Let $\delta=\varepsilon$. We have

$$
\begin{aligned}
\Phi(0, t, t)<\delta & \Longrightarrow 0+t+t<\varepsilon \\
& \Longrightarrow 2 t<\varepsilon \\
& \Longrightarrow t<\varepsilon .
\end{aligned}
$$

Hence $\Phi$ has property (iv).

Proposition 1.36. The function $\Phi:\left(\mathbb{R}^{+}\right)^{3^{*}} \rightarrow \mathbb{R}^{+}$defined as

$$
\Phi\left(t_{1}, t_{2}, t_{3}\right)= \begin{cases}t_{1}+t_{2}+t_{3} & \text { if } \min \left\{t_{1}, t_{2}, t_{3}\right\} \leq 1, \\ 1+t_{1}+t_{2}+t_{3} & \text { otherwise, }\end{cases}
$$

has properties (i), (ii), (iii), and (iv) specified in Theorem 1.24 and is continuous at $\left(t_{1}, t_{2}\right.$, $\left.t_{3}\right) \in\left(\mathbb{R}^{+}\right)^{3^{*}}$ if $\min \left\{t_{1}, t_{2}, t_{3}\right\} \neq 1$.

Proof. The proof is similar to that of Proposition 1.35.

Proposition 1.37. Let $\Phi:\left(\mathbb{R}^{+}\right)^{3^{*}} \rightarrow \mathbb{R}^{+}$be defined as

$$
\Phi\left(t_{1}, t_{2}, t_{3}\right)=\min \left\{t_{1}+t_{2}, t_{2}+t_{3}, t_{3}+t_{1}\right\} \quad \forall\left(t_{1}, t_{2}, t_{3}\right) \in\left(\mathbb{R}^{+}\right)^{3^{*}} .
$$

Then $\Phi$ is continuous on $\left(\mathbb{R}^{+}\right)^{3^{*}}$ and has properties (i), (ii), (iii), and (iv) specified in Theorem 1.24.

Proof. Let $t_{1}, t_{1}^{\prime}, t_{1}^{\prime \prime}, t_{2}, t_{2}^{\prime}, t_{2}^{\prime \prime}, t_{3}, t_{3}^{\prime}, t_{3}^{\prime \prime} \in \mathbb{R}^{+}$be such that $t_{i} \leq t_{i}^{\prime}+t_{i}^{\prime \prime}$ for all $i=1,2,3$. We have

$$
\begin{gathered}
\left(t_{1}+t_{2}^{\prime}\right)+\left(t_{1}^{\prime \prime}+t_{2}^{\prime \prime}\right) \geq t_{1}+t_{2}^{\prime}+t_{2}^{\prime \prime} \geq t_{1}+t_{2}, \quad\left(t_{1}+t_{2}^{\prime}\right)+\left(t_{2}^{\prime \prime}+t_{3}\right) \geq t_{1}+t_{3}, \\
\left(t_{1}+t_{2}^{\prime}\right)+\left(t_{3}+t_{1}^{\prime \prime}\right) \geq t_{1}+t_{3} .
\end{gathered}
$$

Hence $\left(t_{1}+t_{2}^{\prime}\right)+\min \left\{\left(t_{1}^{\prime \prime}+t_{2}^{\prime \prime}\right),\left(t_{2}^{\prime \prime}+t_{3}\right),\left(t_{3}+t_{1}^{\prime \prime}\right)\right\} \geq \min \left\{t_{1}+t_{2}, t_{1}+t_{3}\right\}$. Similarly, we have

$$
\begin{aligned}
\left(t_{3}^{\prime}+t_{1}\right)+\min \left\{\left(t_{1}^{\prime}+t_{2}\right),\left(t_{2}+t_{3}^{\prime \prime}\right),\left(t_{3}^{\prime \prime}+t_{1}^{\prime}\right)\right\} & \geq \min \left\{t_{1}+t_{2}, t_{1}+t_{3}\right\}, \\
\left(t_{1}^{\prime}+t_{2}\right)+\min \left\{\left(t_{1}^{\prime \prime}+t_{2}^{\prime \prime}\right),\left(t_{2}^{\prime \prime}+t_{3}\right),\left(t_{3}+t_{1}^{\prime \prime}\right)\right\} & \geq \min \left\{t_{1}+t_{2}, t_{2}+t_{3}\right\}, \\
\left(t_{2}+t_{3}^{\prime \prime}\right)+\min \left\{\left(t_{1}+t_{2}^{\prime}\right),\left(t_{2}^{\prime}+t_{3}^{\prime}\right),\left(t_{3}^{\prime}+t_{1}\right)\right\} & \geq \min \left\{t_{1}+t_{2}, t_{2}+t_{3}\right\}, \\
\left(t_{2}^{\prime \prime}+t_{3}\right)+\min \left\{\left(t_{1}+t_{2}^{\prime}\right),\left(t_{2}^{\prime}+t_{3}^{\prime}\right),\left(t_{3}^{\prime}+t_{1}\right)\right\} & \geq \min \left\{t_{1}+t_{2}, t_{2}+t_{3}\right\}, \\
\left(t_{3}+t_{1}^{\prime \prime}\right)+\min \left\{\left(t_{1}^{\prime}+t_{2}\right),\left(t_{2}+t_{3}^{\prime \prime}\right),\left(t_{3}^{\prime \prime}+t_{1}^{\prime}\right)\right\} & \geq \min \left\{t_{2}+t_{3}, t_{3}+t_{1}\right\} .
\end{aligned}
$$

We have

$$
\left(t_{2}^{\prime}+t_{3}^{\prime}\right)+\left(t_{3}^{\prime \prime}+t_{1}^{\prime}\right)+\left(t_{1}^{\prime \prime}+t_{2}^{\prime \prime}\right)=\left(t_{1}^{\prime}+t_{1}^{\prime \prime}\right)+\left(t_{2}^{\prime}+t_{2}^{\prime \prime}\right)+\left(t_{3}^{\prime}+t_{3}^{\prime \prime}\right) \geq t_{1}+t_{2}+t_{3} .
$$

Hence

$$
\begin{aligned}
\min \left\{t_{1}+t_{2}, t_{2}+t_{3}, t_{3}+t_{1}\right\} \leq & \min \left\{\left(t_{1}+t_{2}^{\prime}\right),\left(t_{2}^{\prime}+t_{3}^{\prime}\right),\left(t_{3}^{\prime}+t_{1}\right)\right\} \\
& +\min \left\{\left(t_{1}^{\prime}+t_{2}\right),\left(t_{2}+t_{3}^{\prime \prime}\right),\left(t_{3}^{\prime \prime}+t_{1}^{\prime}\right)\right\} \\
& +\min \left\{\left(t_{1}^{\prime \prime}+t_{2}^{\prime \prime}\right),\left(t_{2}^{\prime \prime}+t_{3}\right),\left(t_{3}+t_{1}^{\prime \prime}\right)\right\} .
\end{aligned}
$$


Hence $\Phi\left(t_{1}, t_{2}, t_{3}\right) \leq \Phi\left(t_{1}, t_{2}^{\prime}, t_{3}^{\prime}\right)+\Phi\left(t_{1}^{\prime}, t_{2}, t_{3}^{\prime \prime}\right)+\Phi\left(t_{1}^{\prime \prime}, t_{2}^{\prime \prime}, t_{3}\right)$ whenever $\left(t_{1}, t_{2}, t_{3}\right)$, $\left(t_{1}, t_{2}^{\prime}, t_{3}^{\prime}\right),\left(t_{1}^{\prime}, t_{2}, t_{3}^{\prime \prime}\right),\left(t_{1}^{\prime \prime}, t_{2}^{\prime \prime}, t_{3}\right) \in\left(\mathbb{R}^{+}\right)^{3^{*}}$ and $t_{i} \leq t_{i}^{\prime}+t_{i}^{\prime \prime}$ for all $i=1,2$, 3. Hence $\Phi$ has property (iii) specified in Theorem 1.24.

REMARK 1.38. Let $(X, \rho)$ be a $D$-metric space and $\left\{x_{n}\right\}$ a sequence in $X$. If $\left\{x_{n}\right\}$ converges to an element, say $x \in X$, then $\left\{\rho\left(y, z, x_{n}\right)\right\}$ need not converge to $\rho(y, z, x)$ for all $y, z \in X$. The following examples show that it is so, even when every convergent sequence is strongly convergent and has a unique limit and $\rho$-convergence defines a topology on $X$ which is a metric topology. While in the first example we show the existence of a convergent sequence $\left\{x_{n}\right\}$ with limit, say $x$, and elements $y, z$ of $X$ such that $\left\{\rho\left(y, z, x_{n}\right)\right\}$ is convergent but not to $\rho(y, z, x)$, in the second example we show the existence of a convergent sequence $\left\{x_{n}\right\}$ with limit, say, $x$, and elements $y, z$ of $X$ such that $\left\{\rho\left(y, z, x_{n}\right)\right\}$ is not convergent.

EXAMPLE 1.39. Define a function $\Phi:\left(\mathbb{R}^{+}\right)^{3^{*}} \rightarrow \mathbb{R}^{+}$as

$$
\Phi\left(t_{1}, t_{2}, t_{3}\right)= \begin{cases}t_{1}+t_{2}+t_{3} & \text { if } \min \left\{\left|t_{1}-t_{2}\right|,\left|t_{2}-t_{3}\right|,\left|t_{3}-t_{1}\right|\right\} \leq 1 \\ 1+t_{1}+t_{2}+t_{3} & \text { otherwise. }\end{cases}
$$

From Proposition 1.35, we know that $\Phi$ has properties (i), (ii), (iii), and (iv) specified in Theorem 1.24, and that $\Phi$ is continuous at $\left(t_{1}, t_{2}, t_{3}\right)$ if $\min \left\{\left|t_{1}-t_{2}\right|,\left|t_{2}-t_{3}\right|, \mid t_{3}-\right.$ $\left.t_{1} \mid\right\} \neq 1$. Define $\rho: \mathbb{R}^{3} \rightarrow \mathbb{R}^{+}$as $\rho(x, y, z)=\Phi(|x-y|,|y-z|,|z-x|)$ for all $x, y, z \in \mathbb{R}$. Then, from Corollary 1.25 , it follows that $\rho$ is a $D$-metric on $\mathbb{R},(\mathbb{R}, \rho)$ is $\rho$-complete, and $\rho$-convergence defines a topology on $\mathbb{R}$ which is nothing but the usual topology on $\mathbb{R}$. Further, if $\left\{u_{n}\right\} \subseteq \mathbb{R}$ and $u \in \mathbb{R}$, then $\left|u_{n}-u\right| \rightarrow 0$ as $n \rightarrow \infty$ if and only if $\left\{u_{n}\right\}$ converges to $u$ with respect to $\rho$ if and only if $\left\{u_{n}\right\}$ converges to $u$ strongly with respect to $\rho$. Hence every $\rho$-convergent sequence has a unique limit. Let $x_{n}=1+1 / n$ for all $n \in \mathbb{N}$. Then $\left\{x_{n}\right\}$ is a sequence in $\mathbb{R}$. Clearly $\left\{x_{n}\right\}$ converges to 1 in the usual sense. Hence $\left\{x_{n}\right\}$ converges to 1 with respect to $\rho$. Let $x=1, y=3$, and $z=6$. Then we have

$$
\begin{aligned}
& \rho(y, z, x)=\rho(3,6,1)=\Phi(|3-6|,|6-1|,|1-3|)=\Phi(3,5,2) \\
&=10 \quad(\operatorname{since} \min \{|3-5|,|5-2|,|2-3|\}=\min \{2,3,1\}=1), \\
& \rho\left(y, z, x_{n}\right)=\rho\left(3,6,1+\frac{1}{n}\right)=\Phi\left(|3-6|,\left|6-1-\frac{1}{n}\right|,\left|1+\frac{1}{n}-3\right|\right) \\
&=\Phi\left(3,5-\frac{1}{n}, 2-\frac{1}{n}\right) \\
&=11-\frac{2}{n} \quad \forall n \geq 2\left(\operatorname { s i n c e } \operatorname { m i n } \left\{\left|3-5+\frac{1}{n}\right|,|5-2|,\right.\right. \\
&\left.\left.\qquad\left|\left(2-\frac{1}{n}\right)-3\right|\right\}=\min \left\{3,1+\frac{1}{n}, 2-\frac{1}{n}\right\}>1\right)
\end{aligned}
$$

$\longrightarrow 11$ as $n \rightarrow \infty$.

Hence $\left\{\rho\left(y, z, x_{n}\right)\right\}$ does not converge to $\rho(y, z, x)$. 
EXAMPLE 1.40. Define a function $\Phi:\left(\mathbb{R}^{+}\right)^{3^{*}} \rightarrow \mathbb{R}^{+}$as

$$
\Phi\left(t_{1}, t_{2}, t_{3}\right)= \begin{cases}t_{1}+t_{2}+t_{3} & \text { if } \min \left\{t_{1}, t_{2}, t_{3}\right\} \leq 1, \\ 1+t_{1}+t_{2}+t_{3} & \text { otherwise. }\end{cases}
$$

From Proposition 1.36 we know that $\Phi$ has properties (i), (ii), (iii), and (iv) specified in Theorem 1.24, and that $\Phi$ is continuous at $\left(t_{1}, t_{2}, t_{3}\right) \in\left(\mathbb{R}^{+}\right)^{3 *}$ if and only if $\min \left\{t_{1}, t_{2}\right.$, $\left.t_{3}\right\} \neq 1$. Define $\rho: \mathbb{R}^{3} \rightarrow \mathbb{R}^{+}$as $\rho(x, y, z)=\Phi(|x-y|,|y-z|,|z-x|)$ for all $x, y, z \in \mathbb{R}$. Then, from Corollary 1.25 , it follows that $\rho$ is a $D$-metric on $\mathbb{R},(\mathbb{R}, \rho)$ is $D$-complete, and $\rho$-convergence defines a topology on $\mathbb{R}$ which is nothing but the usual topology on $\mathbb{R}$. Further, if $\left\{u_{n}\right\} \subseteq \mathbb{R}$ and $u \in \mathbb{R}$, then $\left|u_{n}-u\right| \rightarrow 0$ as $n \rightarrow \infty$ if and only if $\left\{u_{n}\right\}$ converges to $u$ with respect to $\rho$ if and only if $\left\{u_{n}\right\}$ converges to $u$ strongly with respect to $\rho$. Hence every $\rho$-convergent sequence has a unique limit.

For any $y \in \mathbb{R}$,

$$
\begin{aligned}
\rho\left(y, y+2, y+3-\frac{1}{n}\right) & =\Phi\left(2,1-\frac{1}{n}, 3-\frac{1}{n}\right) \\
& =6-\frac{2}{n} \longrightarrow 6 \text { as } n \longrightarrow \infty, \\
\rho\left(y, y+2, y+3+\frac{1}{n}\right) & =\Phi\left(2,1+\frac{1}{n}, 3+\frac{1}{n}\right) \\
& =1+6+\frac{2}{n} \\
& \longrightarrow 7 \text { as } n \rightarrow \infty .
\end{aligned}
$$

The sequences $\{y+3-1 / n\}$ and $\{y+3+1 / n\}$ both converge to $y+3$. Let

$$
x_{n}= \begin{cases}y+3-\frac{1}{n} & \text { if } n \text { is odd } \\ y+3+\frac{1}{n} & \text { if } n \text { is even. }\end{cases}
$$

Then $\left\{x_{n}\right\}$ converges to $y+3$, but $\left\{\rho\left(y, y+2, x_{n}\right)\right\}$ does not converge.

ACKNOWLEDGMENT. The authors express their heartfelt thanks to Professors B. E. Rhoades and B. C. Dhage for providing them with the reprints of several of their research papers.

\section{REFERENCES}

[1] B. Ahmad, M. Ashraf, and B. E. Rhoades, Fixed point theorems for expansive mappings in D-metric spaces, Indian J. Pure Appl. Math. 32 (2001), no. 10, 1513-1518.

[2] B. C. Dhage, Generalised metric spaces and mappings with fixed point, Bull. Calcutta Math. Soc. 84 (1992), no. 4, 329-336.

[3] _ On generalized metric spaces and topological structure. II, Pure Appl. Math. Sci. 40 (1994), no. 1-2, 37-41.

[4] _ A common fixed point principle in D-metric spaces, Bull. Calcutta Math. Soc. 91 (1999), no. 6, 475-480.

[5] _ On common fixed points of pairs of coincidentally commuting mappings in D-metric spaces, Indian J. Pure Appl. Math. 30 (1999), no. 4, 395-406. 
[6] _ Generalized metric spaces and topological structure. I, An. Ştiinț. Univ. Al. I. Cuza Iaşi. Mat. (N.S.) 46 (2000), no. 1, 3-24.

[7] B. C. Dhage, Smrati Arya, and Jeong Sheok Ume, A general lemma for fixed-point theorems involving more than two maps in D-metric spaces with applications, Int. J. Math. Math. Sci. 2003 (2003), no. 11, 661-672.

[8] B. C. Dhage, A. M. Pathan, and B. E. Rhoades, A general existence principle for fixed point theorems in D-metric spaces, Int. J. Math. Math. Sci. 23 (2000), no. 7, 441-448.

[9] B. C. Dhage and B. E. Rhoades, A comparison of two contraction principles, Math. Sci. Res. Hot-Line 3 (1999), no. 8, 49-53.

[10] - On common fixed points of quasi-contraction mappings in D-metric spaces, Indian J. Pure Appl. Math. 33 (2002), no. 5, 677-690.

[11] _ Proving fixed point theorems in D-metric spaces via general existence principles, Indian J. Pure Appl. Math. 34 (2003), no. 4, 609-624.

[12] J. S. Ume, Remarks on nonconvex minimization theorems and fixed point theorems in complete D-metric spaces, Indian J. Pure Appl. Math. 32 (2001), no. 1, 25-36.

[13] J. S. Ume and J. K. Kim, Common fixed point theorems in D-metric spaces with local boundedness, Indian J. Pure Appl. Math. 31 (2000), no. 7, 865-871.

[14] T. Veerapandi and K. Chandrasekhara Rao, Fixed points in Dhage metric spaces, Pure Appl. Math. Sci. 43 (1996), no. 1-2, 9-14.

S. V. R. Naidu: Department of Applied Mathematics, Andhra University, Visakhapatnam 530 003, India

E-mail address: svrnaidu@hotmai 1 .com

K. P. R. Rao: Department of Applied Mathematics, Nagarjuna University Post Graduate (N.U.P.G.)

Centre, Acharya Nagarjuna University, Nuzvid 521 201, India

E-mail address: kprrao2004@yahoo.com

N. Srinivasa Rao: Department of Applied Mathematics, Nagarjuna University Post Graduate (N.U.P.G.) Centre, Acharya Nagarjuna University, Nuzvid 521 201, India

E-mail address: srinivasunimma1a@yahoo.co.in 


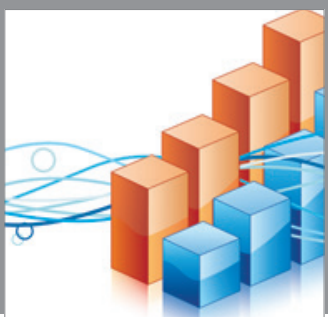

Advances in

Operations Research

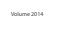

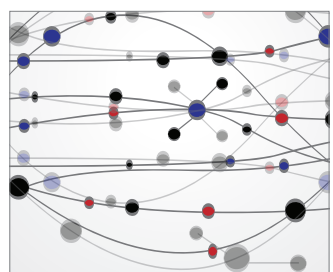

\section{The Scientific} World Journal
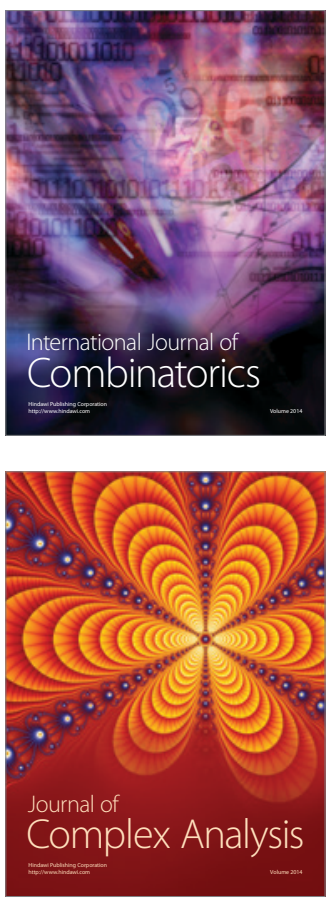

International Journal of

Mathematics and

Mathematical

Sciences
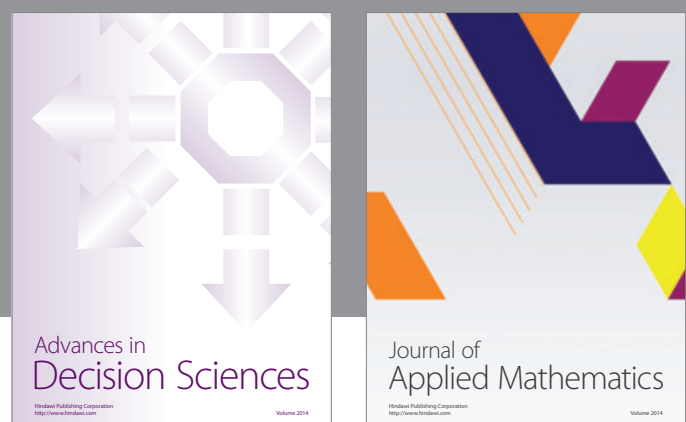

Journal of

Applied Mathematics
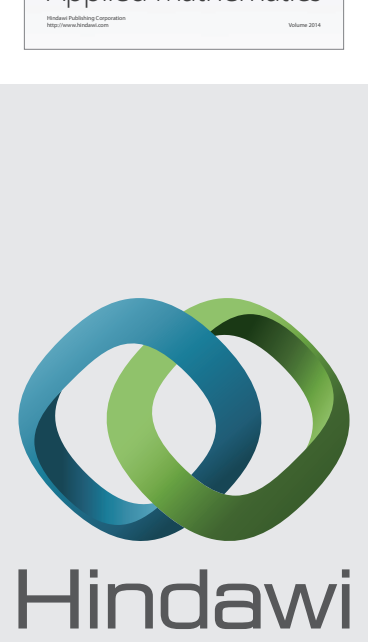

Submit your manuscripts at http://www.hindawi.com
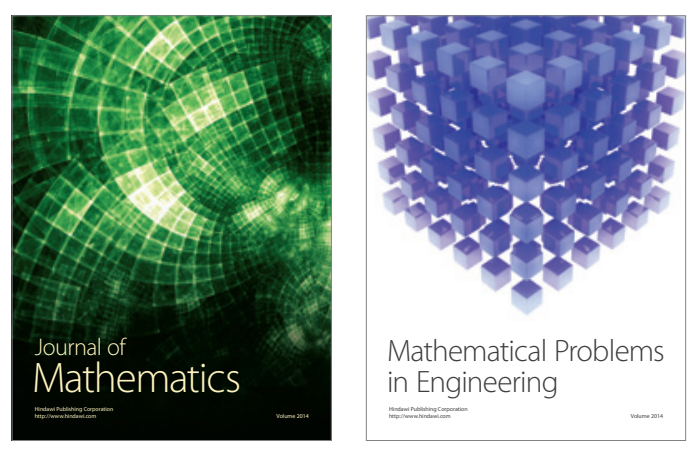

Mathematical Problems in Engineering
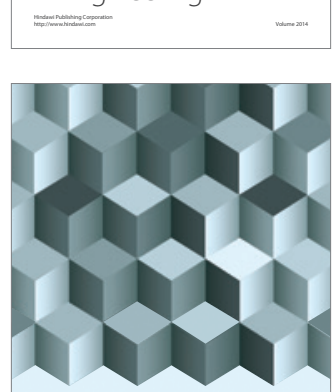

Journal of

Function Spaces
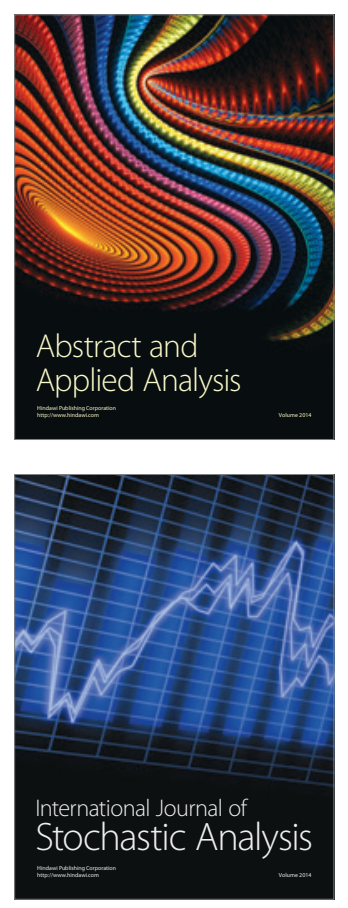

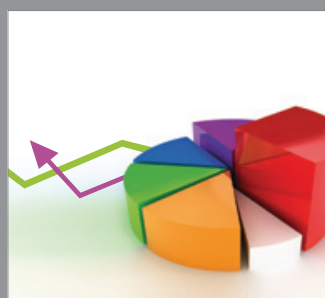

ournal of

Probability and Statistics

Promensencen
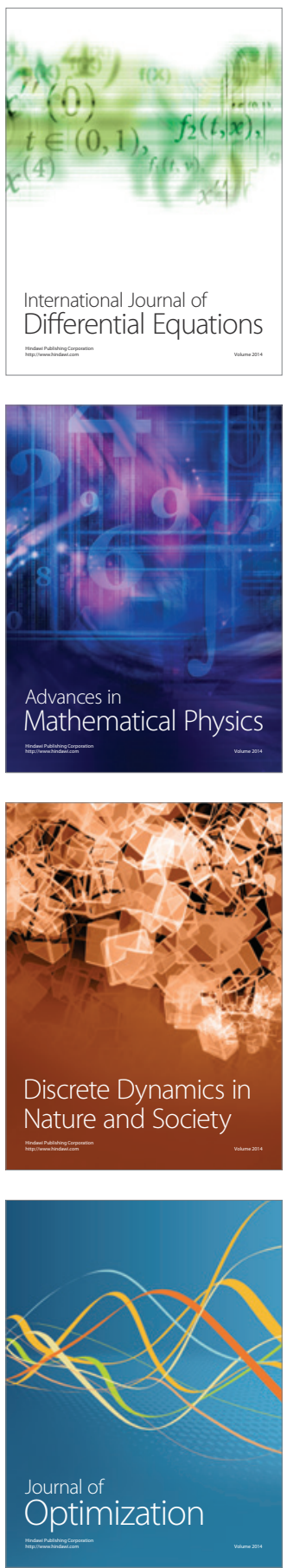